\title{
Multi-hallmark long noncoding RNA maps reveal non-small cell lung cancer vulnerabilities
}

4 Authors

5 Roberta Esposito ${ }^{1,2,3, *}$, Taisia Polidori ${ }^{1,2,4, *}$, Dominik F. Meise ${ }^{1,2}$, Carlos Pulido6 Quetglas $^{1,2,4}$, Panagiotis Chouvardas ${ }^{1,2}$, Stefan Forster ${ }^{1,2}$, Paulina Schaerer ${ }^{1,2}$, Andrea 7 Kobel $^{1,2}$, Juliette Schlatter ${ }^{1,2}$, Michaela Roemmele ${ }^{1,2}$, Emily S. Westemeier ${ }^{5}$, Lina $8 Z_{\text {Zhu }}^{6,7,8}$, Andrés Lanzós ${ }^{1,2,4}$, Hugo A. Guillen-Ramirez ${ }^{1,2}$, Giulia Basile ${ }^{1,2}$, Irene 9 Carrozzo $^{1,2}$, Adrienne Vancura ${ }^{1,2,3}$, Sebastian Ullrich ${ }^{9}$, Alvaro Andrades ${ }^{10,11,12}$, Dylan 10 Harvey ${ }^{14}$, Pedro P. Medina ${ }^{10,11,12}$, Patrick C. Ma ${ }^{13}$, Simon Haefliger ${ }^{1,2}$, Xin Wang ${ }^{6,7,8}$, Ivan Martinez ${ }^{5}$, Adrian Ochsenbein ${ }^{1,2}$, Carsten Riether ${ }^{1,2}$, Rory Johnson ${ }^{1,2,14,15,16}$

4. Graduate School of Cellular and Biomedical Sciences, University of Bern, 3012 Bern, Switzerland. 5. Department of Microbiology, Immunology \& Cell Biology, West Virginia University Cancer Institute, School of Medicine,
West Virginia University, Morgantown, West Virginia.

8. Key Laboratory of Biochip Technology, Biotech and Health Centre, Shenzhen Research Institute, City University of Hong Kong, Shenzhen, Guangdong Province, China.

9. Centre for Genomic Regulation (CRG), The Barcelona Institute for Science and Technology, Barcelona (BIST), Catalonia, Spain.

10. GENYO, Centre for Genomics and Oncological Research, Pfizer/University of Granada/Andalusian Regional Government, Av. de la llustración 114, 18016 Granada, Spain.

11. Instituto de Investigación Biosanitaria (ibs. Granada), Av. Fuerzas Armadas 2, 18014 Granada, Spain. Granada, Spain.

13. Penn State Cancer Institute, Penn State Health Milton S. Hershey Medical Center, Pennsylvania State University, Hershey, Pennsylvania.

14. School of Biology and Environmental Science, University College Dublin, Dublin D04 V1W8, Ireland.

\section{Author list footnotes}

* These authors contributed equally and are listed in alphabetical order

${ }^{16}$ Correspondence: rory.johnson@ucd.ie, +353851840699 
55

\section{6}

57 58

\section{Abstract}

Long noncoding RNAs (IncRNAs) are widely dysregulated in cancer, yet their functional roles in cellular disease hallmarks remain unclear. Here we employ pooled CRISPR deletion to perturb all 831 IncRNAs in KRAS-mutant non-small cell lung cancer (NSCLC), and measure their contribution to proliferation, chemoresistance and migration across two cell backgrounds. Integrative analysis of this data outperforms conventional "dropout" screens in identifying cancer genes, while prioritising diseaserelevant IncRNAs with pleiotropic and background-independent roles. Altogether 60 high-confidence oncogenic IncRNAs are active in NSCLC, the majority identified here for the first time, and which tend to be amplified and overexpressed in tumours. A follow-up antisense oligonucleotide (ASO) screen shortlisted two candidates, Cancer Hallmarks in Lung LncRNA (CHiLL 1\&2), whose knockdown consistently suppressed cancer hallmarks in a variety of 2D and 3D tumour models. Molecular phenotyping reveals that CHiLL $1 \& 2$ control cellular-level phenotypes via distinct transcriptional networks converging on common oncogenic pathways. In summary, this work reveals a multi-dimensional functional IncRNA landscape underlying NSCLC that contains potential therapeutic vulnerabilities.

\section{Keywords:}

CRISPR; IncRNA; long noncoding RNA; cancer; non-small cell lung cancer; NSCLC; RNA therapeutics; antisense oligonucleotides. 


\section{Introduction}

Non-small cell lung cancer (NSCLC) is the leading cause of cancer deaths worldwide (1), and available therapies face a combination of challenges in undruggable mutations, toxicity and therapy resistance (2-4). The most common subtype, carrying activating KRAS mutations $\left(\mathrm{KRAS}^{+}\right)$, is routinely treated with cytotoxic platinum chemotherapy, and newly-approved targeted therapies only extend life by few months $(5,6)$.

A fertile source for new therapeutic targets is long noncoding RNAs (IncRNAs), with a population likely to exceed 100,000 , of which $>98 \%$ remain uncharacterised (710). Hundreds of IncRNAs have been implicated in disease hallmarks across cancer types via a variety of mechanisms (11-14). Examples such as SAMMSON (melanoma) and IncGRS-1 (glioma) have attracted attention as drug targets, thanks to tumour cells' potent and specific sensitivity to their inhibition via antisense oligonucleotide (ASO) therapies $(15,16)$. Nonetheless, the extent and nature of IncRNAs promoting the interlocking pathological hallmarks in a given tumour remains unclear.

Efforts to identify IncRNA therapeutic targets have accelerated with the advent of CRISPR-Cas genome-editing, which can be used to silence gene expression via targeted genomic deletions or transcriptional inhibition, and is readily scaled transcriptome-wide via pooling (17). CRISPR screens have revealed scores of IncRNAs promoting disease hallmarks of cell proliferation, pathway activation and therapy resistance (18-20).

A critical challenge in drug discovery is the poor validation rate of preclinical targets discovered in vitro (21). Highly-focussed single background / single hallmark screen designs, including those above, are vulnerable to discovering IncRNAs promoting cell-line specific phenotypes that do not generalise to the disease in question (15). Supporting this, recent CRISPR-inhibition (CRISPRi) screens demonstrated highly specific effects for IncRNAs in cell lines from six distinct cancer types (18). However, the critical question of whether this also affects cell lines from the same cancer type has not been addressed. Thus, to maximise the utility of discovered hits, an ideal screen should prioritise IncRNA targets that are both pleiotropic (impact multiple disease hallmarks) and background-independent (effective regardless of cell model). 
Here, we comprehensively map the functional IncRNA landscape of $K R A S^{+}$

93 NSCLC. We perform 10 disease-specific CRISPR screens for IncRNAs promoting 94 three cancer hallmarks in two cell models. We reconstruct the functional IncRNA 95 landscape of NSCLC, revealing a catalogue of therapeutic vulnerabilities. These 96 IncRNAs connect to cancer hallmarks via complex transcriptional networks, and can 97 be targeted by potent, low toxicity and on-target ASOs, representing promising future 98 therapeutics (22). 
Results

\section{A versatile CRISPR screening pipeline for long non-coding RNAs in NSCLC}

To identify IncRNAs promoting KRAS ${ }^{+}$NSCLC, we adapted the DECKO (dual excision CRISPR knock-out) CRISPR-deletion (CRISPR-del) system to highthroughput pooled format $(17,23)$ (Figure 1a). This approach achieves loss-of-function perturbations by deleting target genes' transcription start site (TSS) via paired guide RNAs (pgRNAs), and effectively inhibits gene expression (24-27).

We developed a screening library to comprehensively interrogate the NSCLC IncRNA transcriptome. We integrated and filtered published $(10,28,29)$ and in-house annotations $(30,31)$ (Figure 1b), for a final target set of 831 IncRNAs, corresponding to 998 high-confidence TSSs, henceforth named "Candidate_1" and so on (Figure S1a). (Figure 1c and 1d; see Methods). To these we added pgRNAs targeting neutral control loci (not expected to influence cell phenotype) and positive control proteincoding genes (PCGs) (with known roles in cell proliferation and cisplatin resistance) (Figure 1d).

These targets form the basis for 'libDECKO-NSCLC1', a CRISPR-deletion library with a depth of 10 unique pgRNAs per target, comprising altogether 12,000 pgRNAs (Figure 1d and File S1). After cloning into the DECKO backbone (Figure S1b), sequencing revealed high quality in terms of sequence identity $(60.8 \%$ perfect match across both spacers) and coverage ( $90^{\text {th }}$ to $10^{\text {th }}$ percentile count ratios: 4.6 -fold) (32) (Figure S1c).

To identify hits of general relevance to NSCLC, we performed parallel experiments in two widely-used KRAS ${ }^{+}$NSCLC models, A549 and H460(33,34). Nonclonal cell lines were generated that stably express high-levels of Cas9 protein (35), as evidenced by blue fluorescent protein (BFP) (Figure 1e). Targeting known NSCLCpromoting IncRNA DNMBP-AS1 (Candidate_331) (36), resulted in deletion of its promoter region and loss of expression (Figure 1f), supporting the effectiveness of the 
Figure 1

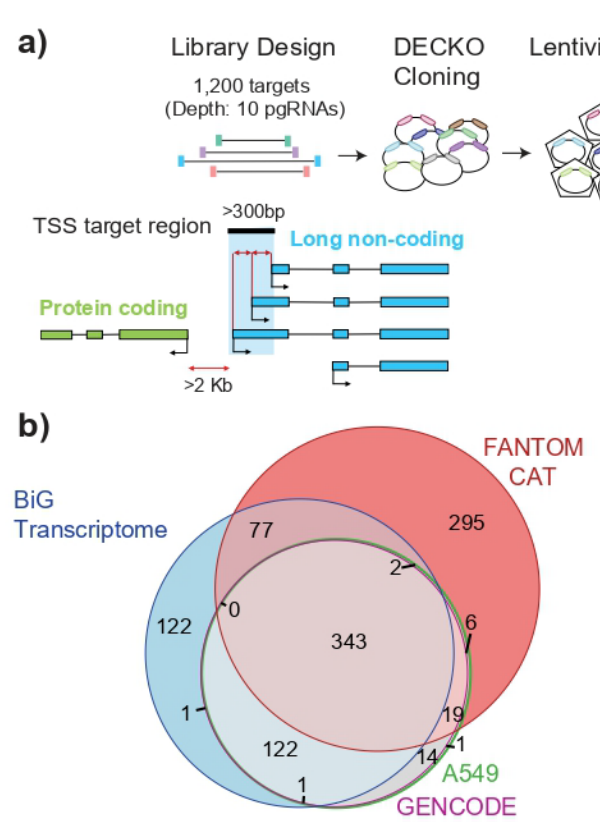

c) Target IncRNAs, RNA-seq

d)
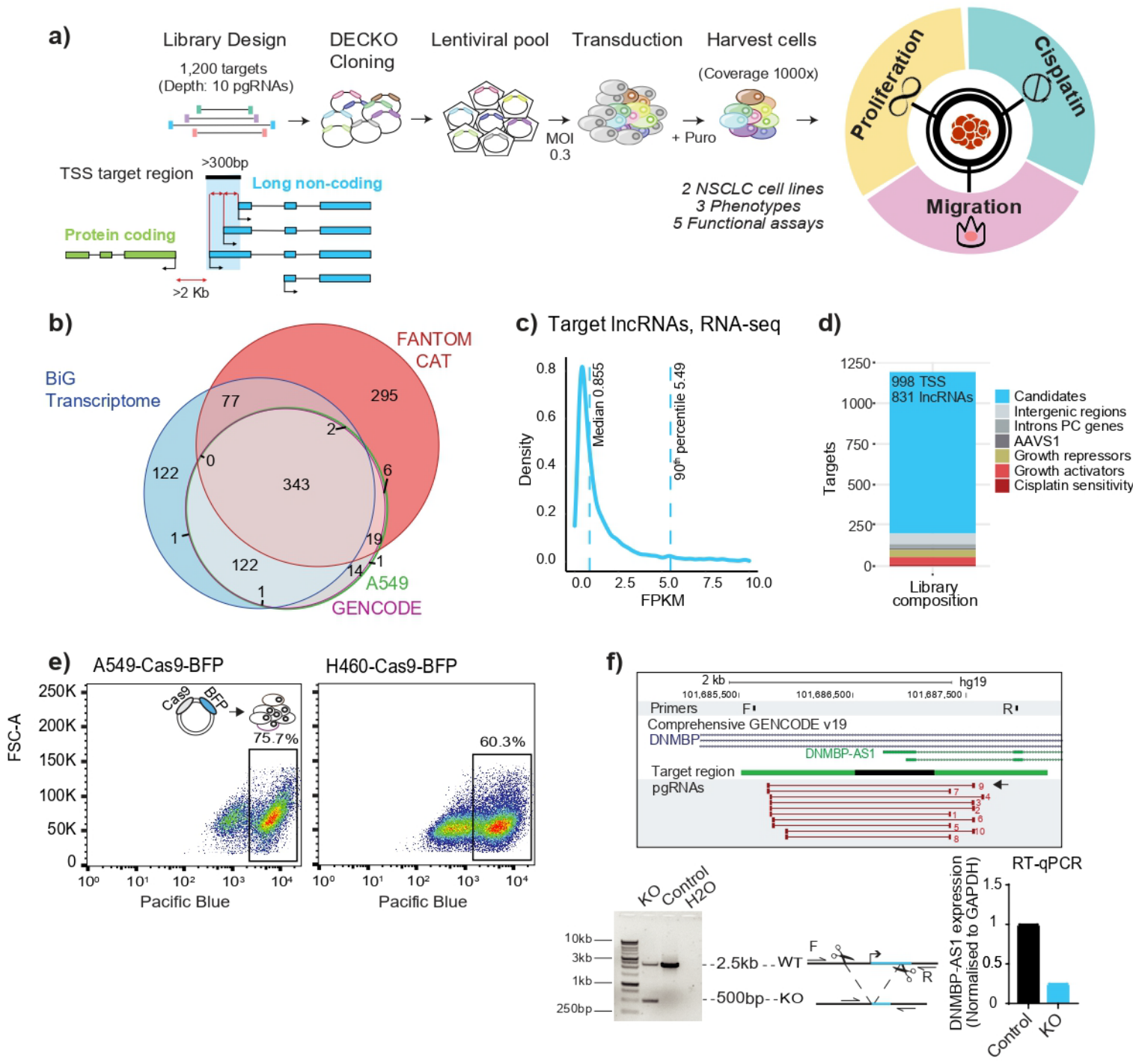

127 Figure 1. Multi-hallmark CRISPR discovery of IncRNAs promoting non-small cell lung

128 cancer. a) CRISPR-deletion pooled screening strategy for IncRNAs promoting NSCLC

129 hallmarks. b) Gene annotations used for candidates' selection. Numbers indicate IncRNA

130 gene loci. c) Expression of targeted IncRNAs in A549 cells. d) Library composition, in terms

131 of targeted regions. Note that some IncRNA loci are represented by $>1$ targeted transcription

132 start site (TSS). e) Fluorescence activated cell sorting (FACS) was used to sort stable Cas9

133 expressing cells based on expression of a Blue Fluorescent Protein (BFP) marker. Boxes

134 indicated the sorted cell populations used in screens. f) One member of the screening library,

135 DNMBP-AS1, was targeted by CRISPR-deletion in A549 cells. The gene locus is shown in the

136 upper panel, including genotyping PCR primers ( $F, R)$, transcription start site (TSS) target

137 region (black), and library paired guide RNAs (pgRNAs, red bars). The pgRNA used here is

138 indicated by the arrow. Below left: PCR using indicated primers with template genomic DNA

139 (gDNA) from cells transfected with non-targeting pgRNA (Control) or DNMBP-AS1 TSS 
pgRNA (KO). The expected lengths for wild-type and deletion amplicons are indicated. Below right: Quantitative reverse transcriptase PCR (RT-PCR) measurement of DNMBP-AS1 RNA.

\section{Multi-phenotype mapping of NSCLC IncRNAs}

Cancers thrive via a variety of phenotypic "hallmarks" (37). Previous CRISPR screens have been limited to a single hallmark, either proliferation or drug resistance $(15,18,38-40)$, and usually focussed on a negative "drop-out" format, where pgRNAs for genes of interest are depleted.

For more comprehensive and biomedically-relevant vista of NSCLC IncRNAs, we adapted pooled screening to read out distinct hallmarks of proliferation, chemoresistance and invasion (Figures $2 \mathrm{a}-\mathrm{c}$ ). To boost sensitivity, we implemented complementary "positive" screens, where pgRNAs of interest are enriched. Thus, to identify IncRNAs promoting cell fitness and proliferation, we combined (i) a classical drop-out, where targets' pgRNAs become depleted, and (ii) a positive screen using CFSE (Carboxyfluorescein succinimidyl ester) dye to identify growth-promoting IncRNAs by their pgRNAs enrichment in slow-growing cells (Figure 2a) (41).

As expected, pgRNAs for positive-control genes were significantly depleted in drop-out screens, while neutral controls were not (Figure $2 \mathrm{~d}$ ). To gauge the LOF efficiency of promoter deletion, pgRNAs targeting positive-control protein-coding genes had been split between two distinct modalities: (1) conventional open reading frame (ORF) mutation, expected to yield maximal LOF; and (2) promoter-deletion, similar to IncRNAs. Promoter-deletion pgRNAs displayed a detectable but lower phenotypic impact, indicating that a CRISPR-del screens for IncRNAs face intrinsically lower sensitivity compared to ORF-targeting screens for PCGs (Figure S2a).

Using biologically-replicated drop-out screens, 77 IncRNAs were identified as necessary for proliferation of A549 cells. These include known NSCLC IncRNAs, such as LINC00324 (42), ZFAS1 (43), MIR31HG (44), SBF2-AS1 (45), LINC00680 (46) and LINC00511 (47), that was also found in H460. In addition, IncRNAs identified in other cancer types include LUNAR1 (48), HEIH (49) and LINC00910 (50) (Figure 2e).

The factors influencing pgRNA deletion efficiency are poorly understood. Using growth phenotype as a proxy for deletion efficiency, we observed expected correlation 
172 algorithm) (Figure S1d). On the other hand, we found no relationship with pgRNA 173 orientation (Figure S1e), and a weak tendency for larger deletions to produce stronger 174 phenotypes, possibly due to greater impact on IncRNA expression (Figure S1f).

175 Next, we compared equivalent drop-out screens in the two NSCLC backgrounds. 176 There was a significant concordance amongst identified targets, driven mainly by 177 positive controls (Figure 2f). To strengthen these data, we performed complementary 178 CFSE screens in the same cells. As expected, these positive screens displayed anticorrelation with drop-out results in H460 cells, although not in A549 cells, possibly for technical reasons (Figure S2b).

Patients with $\mathrm{KRAS}^{+}$tumours are usually treated with cytotoxic platinum-based chemotherapeutics, but tumours frequently evolve resistance (51). To identify IncRNAs promoting chemoresistance, we again employed complementary screens (Figure 2B) at carefully chosen cisplatin concentrations (Figures S2d and S2e). As before, correlated results were observed across cell backgrounds (Figure 2g), and PCGs with known roles in cisplatin resistance were correctly identified (red points in Figure 2g). As expected, complementary survival (negative) and death (positive) screens were anti-correlated for high cisplatin dose (IC80) (Figure S2c).

Migration is a key hallmark underlying invasion and metastasis of tumour cells. By isolating cells with rapid or slow migration through a porous membrane for $48 \mathrm{~h}$ (Figures 2c and S2f), we screened for migration-promoting IncRNAs. This yielded 98 IncRNAs, of which seven were already associated with migration and invasion in numerous cancer types (11), including NORAD, DANCR and SNHG29 (52-55). functional IncRNAs in NSCLC hallmarks. 
Figure 2

a)

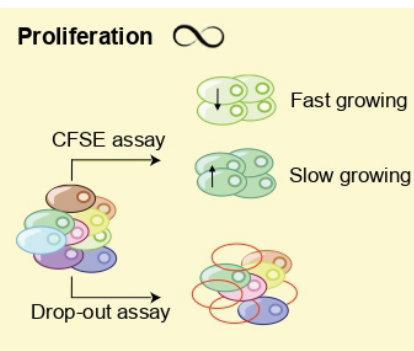

d) Drop-out targets (A549)

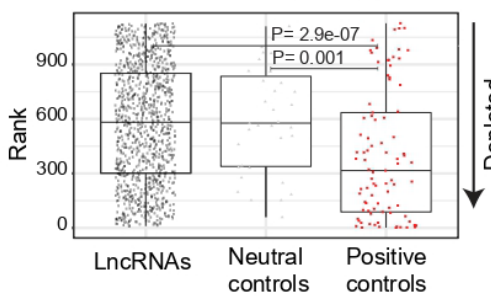

e)
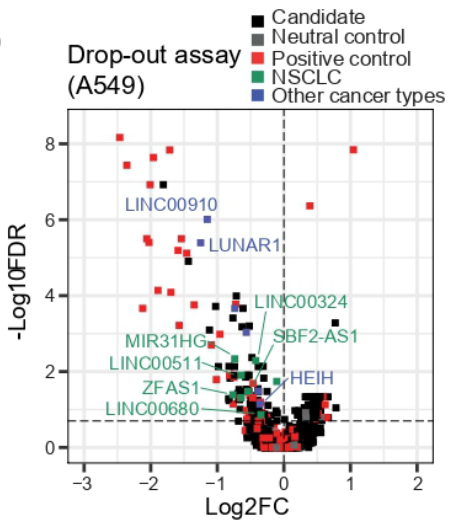

b)

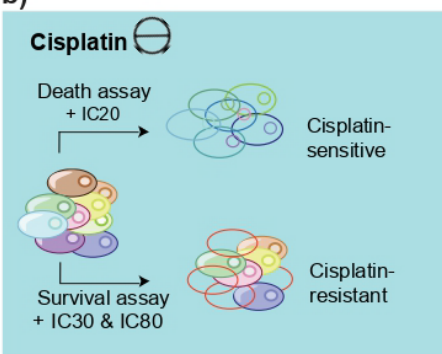

f) Drop-out assay targets

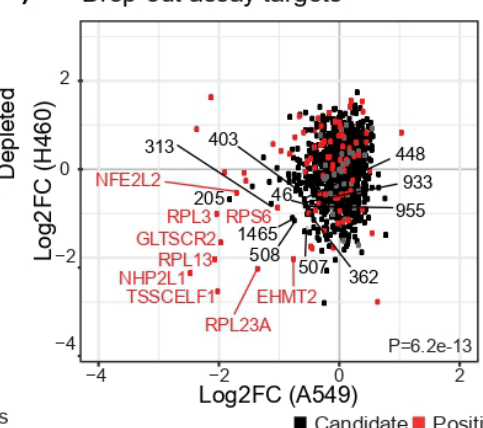

- Candidate $=$ Positive

h) Number of hits in the individual screens

\begin{tabular}{c|ccc|ccc}
\hline FDR<0.2 & \multicolumn{3}{c}{ A549 } & \multicolumn{3}{c}{ H460 } \\
\hline $\begin{array}{c}\text { Phenotypic } \\
\text { Assay }\end{array}$ & $\begin{array}{c}\text { Positive } \\
\text { Controls }\end{array}$ & $\begin{array}{c}\text { Cancer } \\
\text { IncRNAs }\end{array}$ & $\begin{array}{c}\text { Novel } \\
\text { IncRNAs }\end{array}$ & $\begin{array}{c}\text { Positive } \\
\text { Controls }\end{array}$ & $\begin{array}{c}\text { Cancer } \\
\text { IncRNAs }\end{array}$ & $\begin{array}{c}\text { Novel } \\
\text { IncRNAs }\end{array}$ \\
$\begin{array}{c}\text { Drop-out } \\
\text { CFSE }\end{array}$ & 38 & 7 & 67 & 16 & 8 & 57 \\
Survival IC30 & 34 & 2 & 5 & 3 & 0 & 6 \\
Survival IC80 & 22 & 2 & 58 & 12 & 3 & 31 \\
Death IC20 & 13 & 2 & 13 & & 2 & 10 \\
Migration & 31 & 7 & 91 & & & \\
\hline
\end{tabular}

196 Figure 2. Adapting CRISPR screens to cancer hallmarks. a) Proliferation: The strategy 197 employs complementary negative (drop-out) (growth-promoting IncRNAs' pgRNAs are 198 depleted) and positive (CFSE dye) (growth-promoting IncRNAs' pgRNAs are enriched) 199 formats. b) Cisplatin sensitivity: Another complementary strategy is employed. In the negative 200 (drop-out) "survival" screen, cells are exposed to high cisplatin doses (IC30, IC80). 201 Resistance-promoting IncRNAs' pgRNAs will be depleted in surviving cells. In the positive 202 "death" screen, cells that die in response to low cisplatin concentration (IC20) are collected, and enriched pgRNAs identify resistance-promoting IncRNAs. c) Migration: Cells that are capable / incapable of migrating through a porous membrane over a given time period are separately collected. Migration-promoting IncRNAs are identified via their pgRNAs' enrichment in migration-impaired cells. d) LncRNA candidates, neutral and positive controls, ranked by P-value in A549 drop-out screen (statistical significance estimate using Wilcoxon test). e) A549 drop-out screen. Horizontal line indicates cutoff for hits at FDR<0.2. Previously published IncRNAs in NSCLC and other cancers are labelled in green and blue, respectively. 
211 Pearson correlation). g) Comparison of A549 and H460 cisplatin survival screen (Pearson correlation). h) Numbers of screen hits at FDR<0.2

\section{Screen hits can be validated and function via RNA products}

We next tested the reliability of these results by selecting two IncRNA TSSs for further validation, based on their top ranking and consistency between the two cell lines: Candidate_205, identified as top hit in drop-out screens (A549: Log2FC=-1.81, FDR=1.2e-07) and Candidate_509 in both proliferation and cisplatin (A549: Log2FC=1.15, FDR=9.78e-07).

Candidate_205 overlaps the TSS of bidirectional antisense GENCODEannotated genes, LINC00115 and RP11-206L10 (Figure 3a). Candidate_509 targets a TSS shared by several BIGTranscriptome IncRNAs (Figure 3a). Supporting the importance of this locus, it contains two additional hits, Candidate_507 (LINC00910) and Candidate_508 (Figure S2g).

To validate the phenotypic effect of these deletions, we tested individual highscoring pgRNAs (Figure 3b, arrows). Candidate_205 pgRNA efficiently deleted the targeted region (Figure S2h), and while difficulty in designing PCR primers prevented direct testing of deletion by Candidate_509, it effectively decreased RNA levels (Figure S2i). Both pgRNAs yielded potent effects on cell fitness: mCherry+ cells expressing pgRNAs were out-competed by control cells (GFP+, expressing pgRNA for AAVS1), with an effect comparable to inactivation of essential ribosomal gene RPS5 (Figures 3c and S2j). Similar results were observed in a conventional assay (Figure S2k). Furthermore, the pgRNA for Candidate_509 also sensitised cells to cisplatin, consistent with screen results (Figure $3 \mathrm{c}$ ).

It remained ambiguous which of the two genes overlapping the Candidate_205 region drives these effects. Furthermore, genomic deletion cannot distinguish between a DNA-dependent (for example, enhancer) or RNA-dependent mechanism (mature IncRNA, or its transcription). To address both questions, we used two gene-specific ASOs to target each gene. This clearly implicated LINC00115, but not RP11-206L10, 
Similar high validation rates were observed for the migration screens. ASO-

243 knockdown of three hits, Candidate_215 (AC104024.3), Candidate_448 (CECR7) and

244 Candidate_489 (MIR23AHG) resulted in dramatic impairment of A549 migration

245 (Figures 3e and 3f).

246 In summary, these findings support the ability of CRISPR-deletion screens to 247 identify IncRNA genes that promote cancer hallmarks via RNA-dependent 248 mechanisms. 


\section{Figure 3}

a)

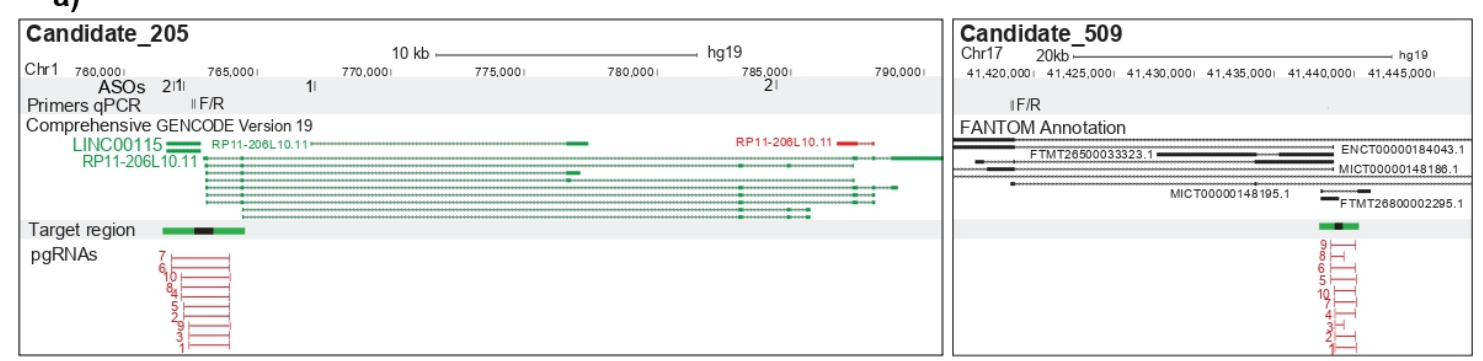

b) Drop-out (A549) Candidate_205

Candidate_509

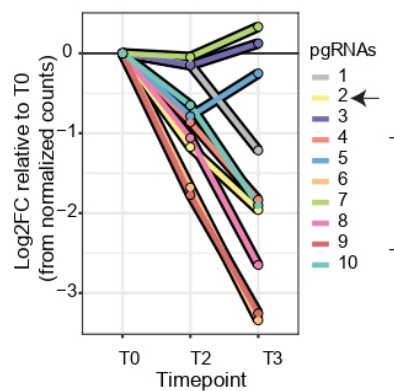

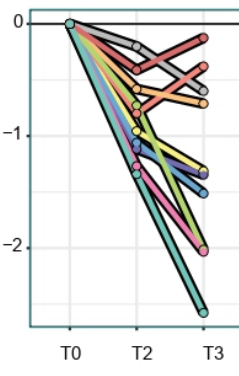

T0 T2 T3

d) RNA-mediated phenotypic assay
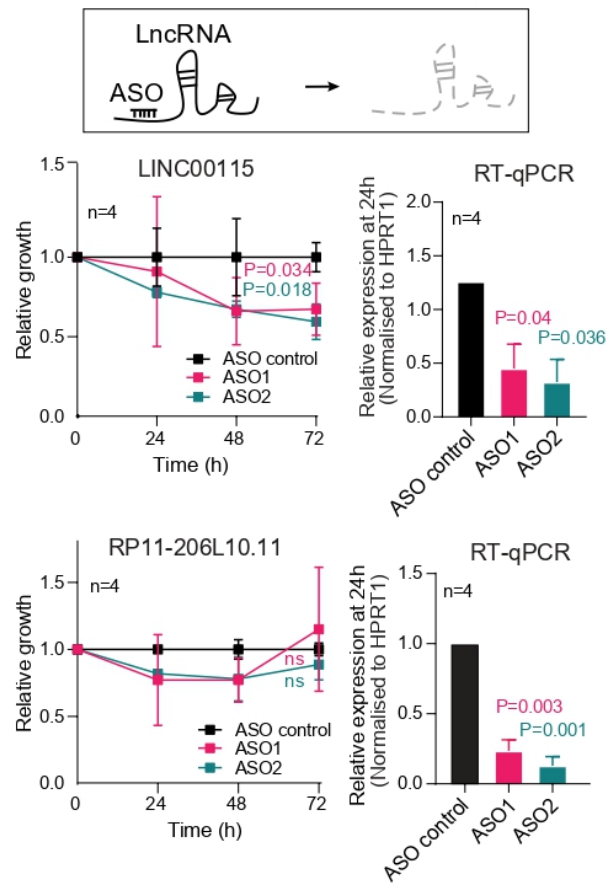

c) Competition assay (A549)
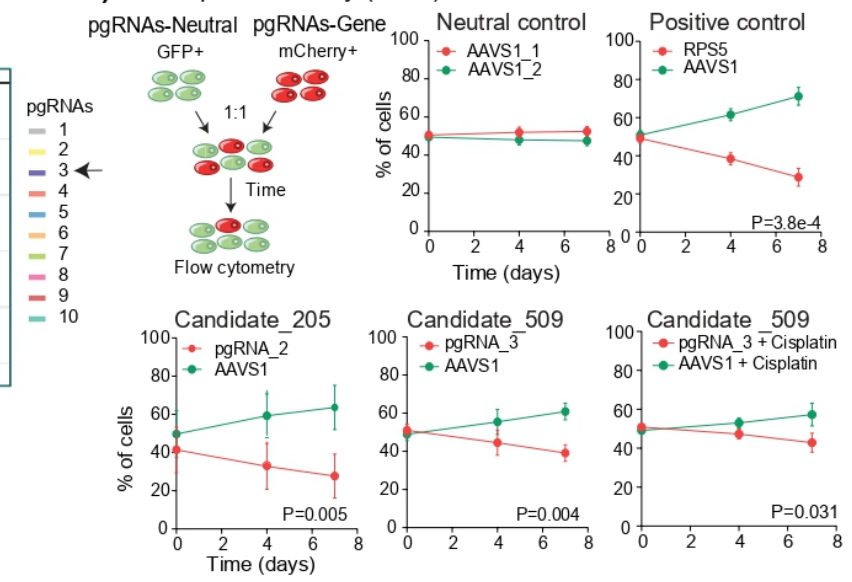

e) Migration assay (A549)
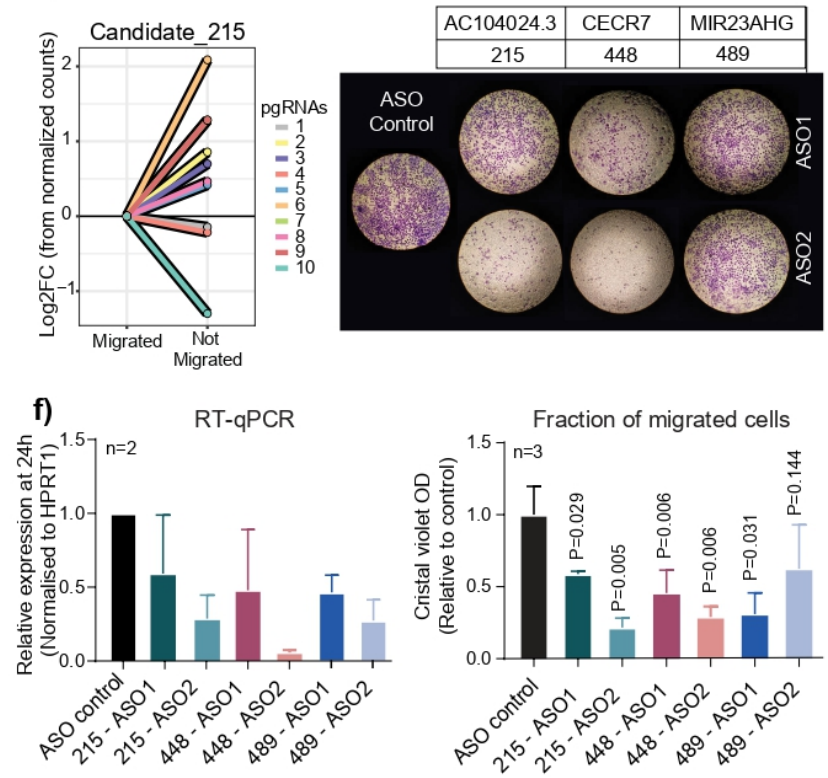

Figure 3. Validation of screen hits shows reproducible phenotypes. a) Candidate_205 (left panel) and Candidate_509 (right panel) loci. Primers and ASO sites are indicated above. The TSS target region and the 10 pgRNAs from the screening library are indicated below. b) Normalised pgRNA counts over the course of the drop-out screen in A549. Arrows indicate pgRNAs that were cloned here for validation. c) Competition assay. Fluorescently-labelled cells carrying pgRNAs for control AAVS1 locus (green, GFP) or indicated targets (red, 
mCherry) were measured by flow cytometry. pgRNAs targeting the ORF of essential ribosomal protein RPS5 were used as positive control. $\mathrm{N}=3$, error bars indicate standard deviation; statistical significance was estimated by Student's $t$ test at the last timepoint. d) ASOs were used to separately target the two IncRNAs sharing the TSS at Candidate_205. For each, two different ASOs were employed (1 and 2) in A549 cells. Upper panels: LINC00115; Lower panels: RP11-206L10.11. Left: cell population; right: RNA expression measured by RT-qPCR. $\mathrm{N}=4$; error bars indicate standard deviation; significance was estimated by one-tailed Student's $t$ test. e) Left: Normalised counts of pgRNAs in migrated and non-migrated cell populations from A549 migration screen. Right: Validation experiments with A549 cell migration across transwell supports over $24 \mathrm{~h}$. Cells were treated with ASOs targeting indicated IncRNAs or a non-targeting control. f) Left: RT-qPCR in A549 cells treated with two distinct ASOs each for Candidate_215, 448 and 489. Expression was normalised to a nontargeting ASO. Right: Crystal violet quantification normalised to non-targeting ASO. Data are plotted as mean \pm SD from three independent biological replicates. Statistical significance was estimated by one-tailed Student's $t$ test.

\section{Multi-hallmark screen integration for target discovery}

We next integrated these data into quantitative and comprehensive map of IncRNAs driving NSCLC hallmarks. To combine diverse screen results while balancing effect size and significance, we created an integrative target prioritisation pipeline (TPP) (Figure 4a). TPP can either be run on all screens for a "pan-hallmark" target ranking, or for individual hallmarks ("hallmark-specific"; see Methods). The panhallmark ranking outperforms common integration methods and individual screens in correctly classifying positive and neutral controls (Figure 4b).

The hallmark-specific values provide a signature for each IncRNA in three functional dimensions, in the context of overall confidence defined by pan-hallmark ranking (Figure 4c). The union of hits from both approaches (FDR<0.2) yielded 111 IncRNAs (Figure 4c). Pan-hallmark analysis alone identified altogether 60 IncRNA hits ( $6 \%$ of those screened; File S3) (FDR<0.2), of which 49 were not previously linked to NSCLC (Figure 4d). As expected, growth-promoting PCG positive controls and known lung cancer IncRNAs, but not neutral controls, are enriched amongst hits. This is supported by independent Enrichment Score Analysis (Figure S3a). Attesting to their value, hits are significantly enriched for disease-associated IncRNAs (Figure S3b), and consistent with previous reports (57), they are more expressed in healthy 
tissues and marginally more evolutionarily conserved (Figure S3c). Hallmark-specific integration yielded 96 hits ( $10 \%$ of those screened) in at least one hallmark, of which 14 are found in two hallmarks, and none in three (Figure S3d).

Previous CRISPR screens have demonstrated highly background-specific roles in proliferation for cell lines from distinct cancer types(18). However, the degree of similarity between such roles between cell models from a given cancer type is not known. Indeed, comparing IncRNA hits from conventional drop-out analysis in A549 and H460 backgrounds revealed a low degree of correlation (Figure 4e left panel). In contrast, pan-hallmark hits display relatively background-independent activity (Figure $4 \mathrm{e}$ right panel), supporting the usefulness of an integrative screening strategy for discovering therapeutic targets.

Cancer-promoting IncRNAs are expected to be upregulated in tumours $(58,59)$.

301 Consistent with this, pan-hallmark hits are significantly higher expressed than non-hits 302 in $\mathrm{KRAS}^{+}$lung tumours (Figure 4f), and are upregulated in tumours compared to 303 adjacent tissue (Figure $4 \mathrm{~g}$ ). Screen hits tend to be amplified, but not depleted, in DNA 304 from tumours (Figures $4 \mathrm{~h}$ and S3e) and cell lines (Figure S3f).

In summary, integration of diverse screens yields accurate maps of functional IncRNAs that are enriched for meaningful clinical features and display cell background-independent activity. 


\section{Figure 4}

a) Target prioritisation pipeline (TPP)

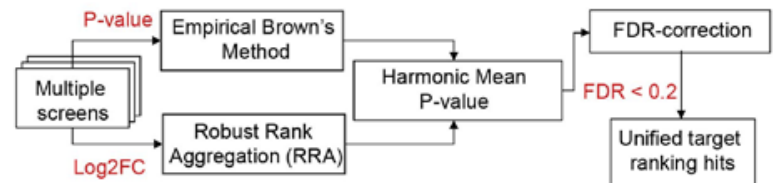

c) Pan-hallmark analysis

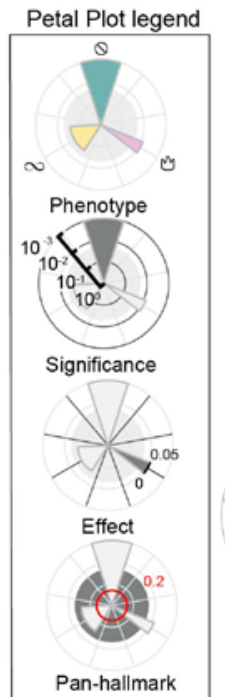

Pan-hallmark

d) Pan-hallmark hits composition

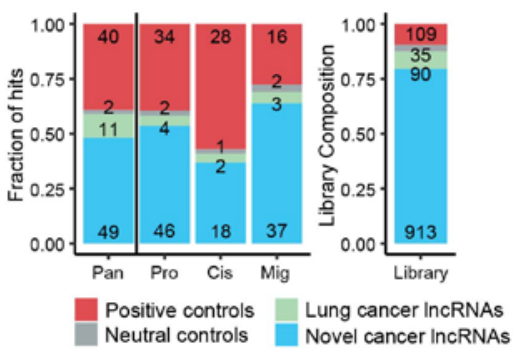

$$
\text { f) }
$$

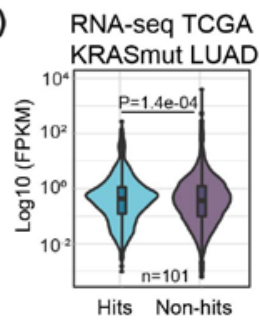

e) Cell line specific effects

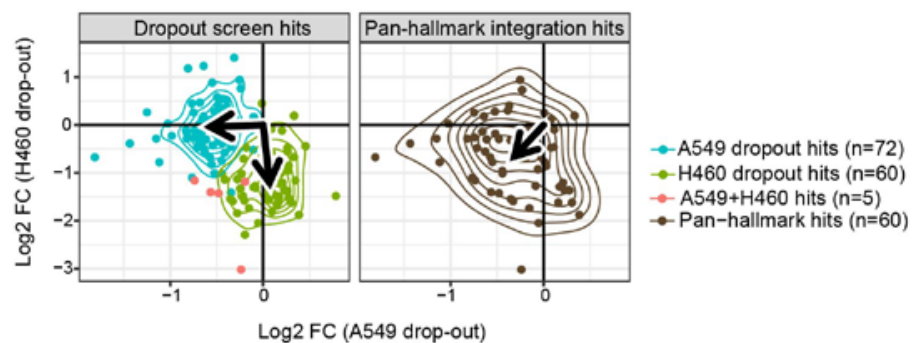

g) RNA-seq TANRIC LUAD patients

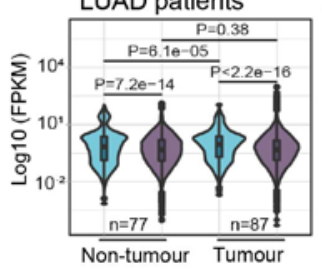

b)

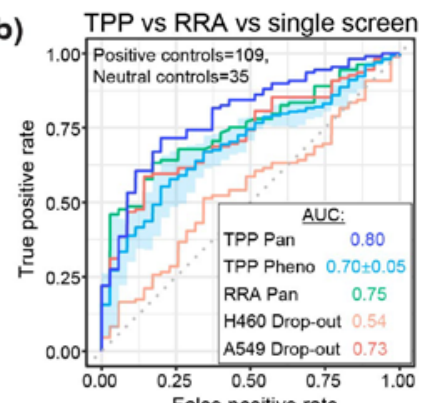

Pan+Pro+Cis Pan+Pro+Mig

Controls:

O Neutral control

Analysis Type:

O Pan-hallmark

$\checkmark$ Phenotype-specific

AC104024.3

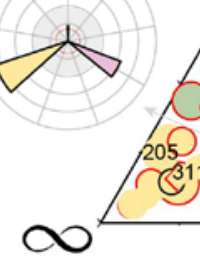

$\diamond \quad 448$

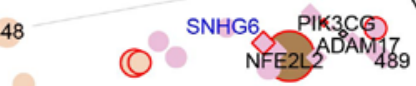

\section{Cy}

308 Figure 4. Functional landscape of IncRNAs in NSCLC. a) Target prioritisation pipeline 309 (TPP) integrates multiple screens to generate a unified hit ranking. TPP employs both effect 310 size (Robust Rank Aggregation; RRA) and statistical significance (empirical Brown's method).

311 b) Comparing performance of screens and integration methods. Performance is measured as 312 the area under the ROC curve (AUC) based on correctly recalling/rejecting library controls 313 (positive and neutral controls, respectively). c) Ternary plot contains all significant hits 314 (FDR<0.2) in pan-hallmark analysis (circles) or individual hallmarks (diamonds). The three 
corners represent the hallmarks, indicated by symbols. The proximity to each corner is driven by the TPP significance calculated for each individual hallmark. The candidates selected for further validations and protein-coding controls are indicated by candidate number or gene name, respectively. Selected IncRNAs previously associated with LUAD are labelled in blue. Petal plots display the hallmark contributions of selected IncRNAs. d) The number of hits discovered in pan-hallmark and individual hallmark screens. Right: The target composition of the screening library for comparison. "Lung cancer IncRNAs" indicate previously-published, functionally-validated IncRNAs in lung cancer(11) e) Scatter plot showing the correlation of the drop-out assay hits (left panel) and the pan-hallmark hits (right panel) in H460 and A549. The arrows point to the geometric median of the respective group. f) Expression of panhallmark hits compared to all other screened IncRNAs (non-hits) in the KRAS ${ }^{+}$samples from the TCGA LUAD cohort ( $n=101)$. Statistical significance was estimated by Welch's $t$-test, onetailed. g) Expression of pan-hallmark hits compared to non-hits in an independent cohort of LUAD samples and healthy tissues (87 tumour; 77 normal)(60). Statistical significance: pairwise two-tailed Student's $t$-test. h) Pan-cancer recurrent amplifications and deletions, estimated in PCAWG cohort. Statistical significance was estimated by Fisher's exact test.

\section{RNA therapeutics targeting NSCLC IncRNAs}

Multi-hallmark IncRNA maps are a resource of targets for therapeutic ASOs(6163). We manually selected ten IncRNAs from top-ranked hits, based on criteria of novelty and lack of protein-coding evidence, and henceforth referred to as "Tier 1". Eight are annotated by GENCODE, and two by either FANTOM CAT or BIGTranscriptome (File S5, Table1). For each candidate, we designed a series of ASOs and managed to identify at least two independent ASOs with $\geq 40 \%$ knockdown potency (Figure S4a).

Next, we tested ASOs' phenotypic effects, in terms of proliferation and cisplatin sensitivity (Figure 5a). For five IncRNAs (Tier 2), we observed reproducible loss of cell proliferation with two distinct ASO sequences, indicating on-target activity(64). To check how broadly applicable these effects are, we re-tested the ASOs in two other $\mathrm{KRAS}^{+}$NSCLC cell lines, H460 and H441 (derived from a pericardial effusion metastasis), and observed similar results (Figure 5a). Consistent with their effects on cisplatin sensitivity, Tier 2 genes' expression is upregulated in response to cisplatin 
Tier 2 IncRNAs are over-expressed in NSCLC tumours, despite this not being a selection criterion (Figure 5b).

It has been proposed that targeting IncRNAs could cause lower side-effects in healthy tissue, although few studies have tested this(15). We evaluated Tier 2 ASOs' effects on a panel of non-transformed lung-derived cells: HBEC3-KT, MRC5-CV1 (both immortalised) and CCD-12Lu (primary). These cells displayed diminished or absent response, particularly for the first two candidate IncRNAs (Figure 5a). Consequently, we narrowed our focus to these "Tier 3" IncRNAs: Candidate_42 (ENSG00000253616) and Candidate_240 (ENSG00000272808), henceforth renamed Cancer Hallmark in Lung LncRNA (CHiLL) 1 and 2, respectively. Both have low protein-coding potential (Figures $5 \mathrm{c}$ and S4d). Replication experiments confirmed the knockdown potency and phenotypic impacts of both ASOs for each gene (Figures 5d, S4c and S4e). ASOs displayed activity in additional KRAS ${ }^{+}$and EGFR-mutant cell lines, suggesting subtype-independent activity (Figure S4f).

CHiLL1 has, to our knowledge, never previously been implicated in cancer. It is located on Chr8 and consists of two annotated isoforms, sharing the first exon (Figure 5c, upper panel) It is localized upstream and on the same strand of the protein-coding gene TNFRSF10B, previously associated with NSCLC(65) although we find no evidence for read through transcription between the two loci (Figures S5a and S5b). Its sequence lacks obvious functional elements (Figure S5c). Supporting its relevance, high expression of CHiLL1 correlates with poor overall survival (Figure S4g).

CHiLL2 (Chr15) comprises four isoforms sharing a common TSS (Figure 5c, lower panel). It is associated with poor prognosis in colon cancer(66), and during preparation of this manuscript, was reported to be an oncogene in gastric cancer(67). It has a likely orthologue in mouse, the uncharacterised Gm44753 (Figure S5f). In contrast to CHiLL1, CHiLL2 exons contain numerous conserved sequences and structures (Figure 6a), and its locus is frequently amplified in cancer genomes (Figure S5d). In TCGA samples, CHiLL2 expression is upregulated in the proximal inflammatory (PI) tumour subtype, which is associated with poorer prognosis (Figures S4h and S4i; PI vs. PP - P=4e-05; PI vs. TRU - P = 0.008).

Three-dimensional (3D) in vitro models represent a more faithful tumour model compared to monolayer cultures(68,69). We delivered CHILL1\&2 ASOs to spheroid 
380

381

382

383

384

385

386

387

388

389

390

391

392

393

394

395

396

397

398

cultures of H441 cells, and observed a reduction in viability approaching that of the positive control, mTOR (Figures 5e and S4j).

Organoids derived from patient-derived xenografts (PDX) recapitulate the therapy response of individual patients(70). Delivery of CHiLL1 ASOs resulted in significant reduction in cell viability of the KRAS $^{+}$human NSCLC organoid BE874 (Figure 5f).

We were curious whether simultaneous targeting of two or more distinct vulnerabilities, via "cocktails" of ASOs, might offer synergistic benefits. Indeed, a 50:50 cocktail of CHiLL1 / CHiLL2 ASOs (Tier 3 cocktail) displayed a greater effect on cell viability, compared to an equal dose of either ASO alone (Figures $5 \mathrm{~g}$ and S4k). A fiveASO cocktail for Tier 2 IncRNAs yielded a similar benefit (Figure $5 \mathrm{~g}$ ). Interestingly, cocktails resulted in no additional toxicity for non-cancerous cells (Figure S4I).

Finally, we asked what fraction of patients might benefit from ASO treatment. RNA-sequencing (RNA-seq) data for TCGA tumours indicates that $78 \%$ express at least one of CHiLL1 and CHiLL2 and might be treated by the Tier 3 cocktail, rising to $92 \%$ for Tier 2 .

Together these results demonstrate that Tier 3 IncRNAs can be targeted by potent and low-toxicity ASOs, which may be beneficial alone or in combination for the majority of NSCLC cases (Figure $5 \mathrm{~h}$ ). 


\section{Figure 5}

a)

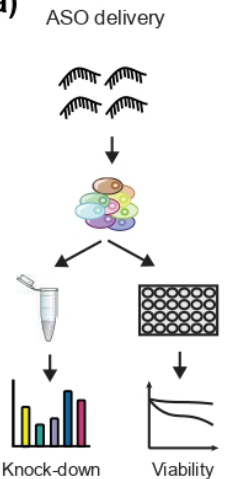

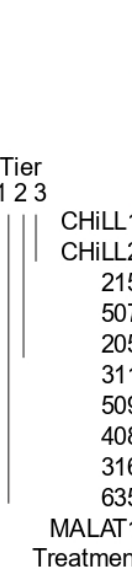

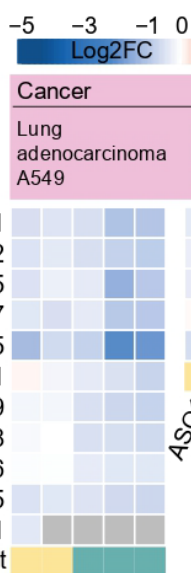

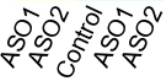

c)

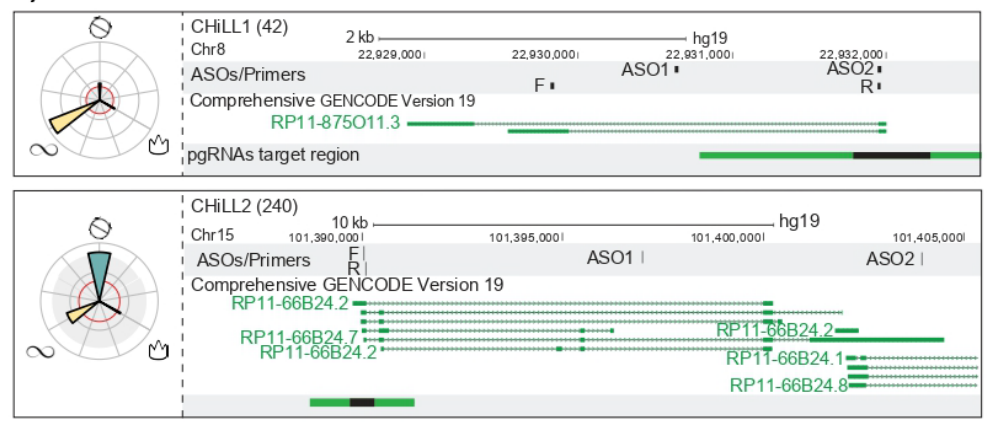

e)

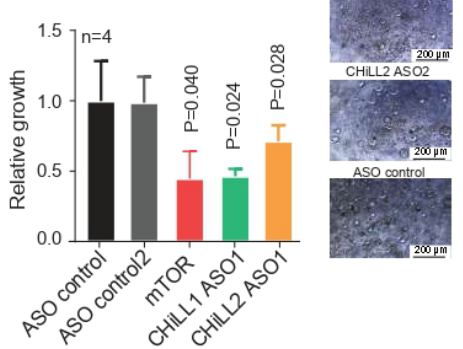

f) NSCLC organoids $\circ$ ASO control

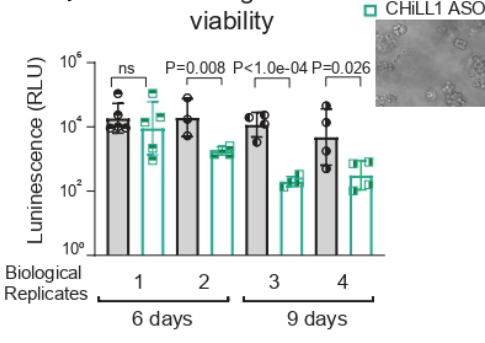

h)

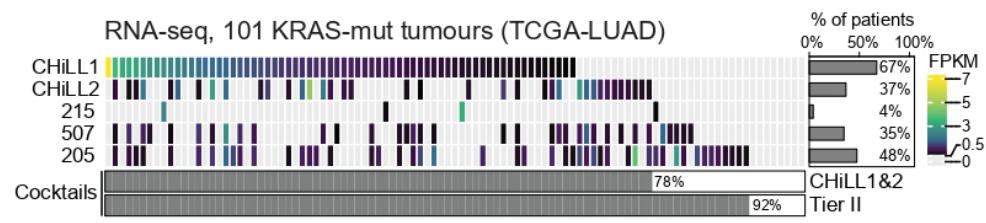

b)
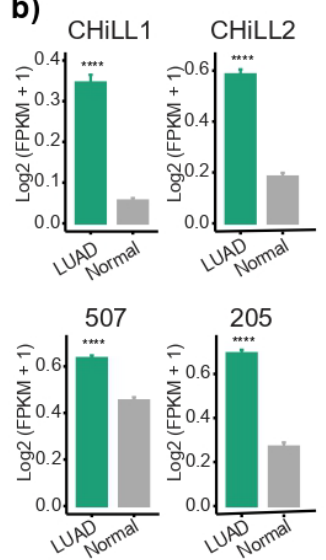

d)
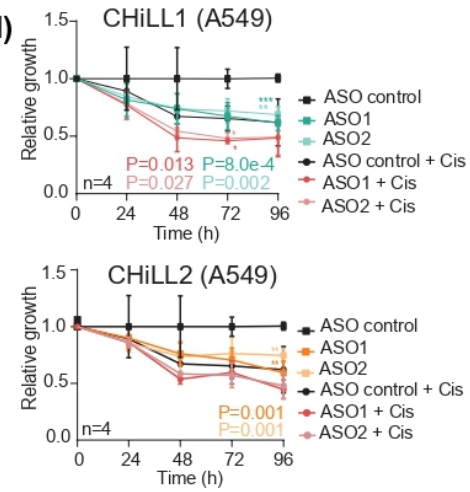

g) ASO Cocktail

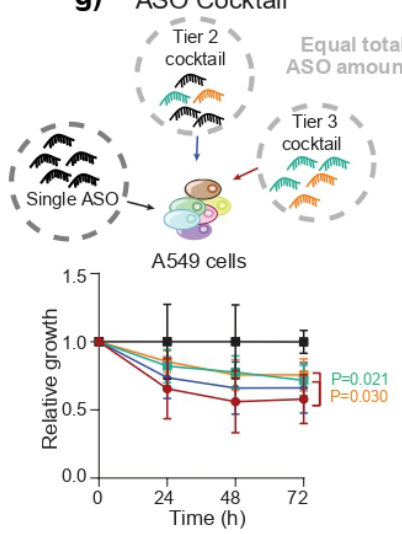

- CHiLL1 ASO1 - Tier 3 cocktail - ASO control

Figure 5. Therapeutic targeting of oncogenic IncRNAs CHiLL1 and CHiLL2. a) Left: Experimental workflow to test knockdown efficiency and phenotypic effect of ASO transfection.

401 Right: Summary of all ASO/cell line results. Rows: Targeted IncRNAs; Columns: ASOs and 402 cell lines. Values reflect the mean log2 fold change in viability following ASO transfection, with respect to a control non-targeting $A S O, n>2$. Numbers to the left indicate library candidate identifiers, and are grouped into Tiers. Each IncRNA is targeted by two independent ASO sequences (1\&2, below). MALAT1 IncRNA is used as positive control. "Normal" cells are nontransformed cells of lung origin. b) Expression of Tier 2 IncRNAs - CHiLL1, CHiLL2, 
Candidate_205 (LINC001150), Candidate_507 (LINC00910) - in TCGA RNA-seq. LUAD: 513

408

409

410

411

412

413

414

415

416

417

418

419

420

421

422

423

424

425

426

427

428

429

430

431

432

433

434

435

436

437

438

439

440 samples, Normal: 59 samples. Statistical significance estimated by $t$-test; ${ }^{* \star \star *} P<0.0001$. Data was not available for Candidate_215 in the TCGA dataset. c) Genomic loci encoding CHiLL1 (upper panel) and CHiLL2 (lower panel). d) A549 cell growth upon transfection with two independent ASOs. Results are normalised to non-targeting control ASO ( $n=4$ biological replicates; error bars: standard deviation; statistical significance: two-tailed Student's $t$ test). e) Left: Viability of H441 spheroid cultures seven days after ASOs transfection (25nM). mTOR ASO was used as positive control ( $n=4$ biological replicates; error bars: standard deviation; one-tailed Student's $t$ test). Right: Representative images (Leica DM IL LED Tissue Culture Microscope). f) Viability of BE874 organoids grown from a KRAS ${ }^{+}$patient-derived xenograft after CHiLL1 ASO transfection ( $n=4$ biological replicates; $n>3$ technical replicates; error bars: standard deviation; one-tailed Student's $t$ test). g) ASO cocktails. Above: For all experiments, the total amount of ASO did not vary $(25 \mathrm{nM})$. Cocktails were composed of equal proportions of indicated ASOs. Below: A549 cell populations, normalised to non-targeting ASO ( $n=4$ biological replicates; error bars: standard deviation; statistical significance: one-tailed Mann Whitney test). $\mathbf{h}$ ) Expression of Tier 2 IncRNAs in KRAS ${ }^{+}$LUAD tumours (TCGA). Each cell represents a patient, and is coloured to reflect expression as estimated by RNA-seq (expression defined as $>0.5$ FPKM). Below, the percentage of patients with at least one IncRNA from the indicated cocktails.

\section{CHiLL1\&2 ASOs regulated cancer hallmarks via distinct modes of action}

We next investigated the modes of action linking CHiLL1\&2 to NSCLC hallmarks. Subcellular localisation yields important mechanistic clues for IncRNAs (71). Surprisingly, despite their similar oncogenic roles, fluorescence in situ hybridisation (FISH) revealed contrasting localisation patterns: CHiLL1 is located principally in the cytoplasm, and CHiLL2 in the nucleus (Figure 6b). Specificity was validated by knockdown (Figure S5e), and results were further corroborated by cell fractionation (Figure 6c).

To gain more detailed mechanistic insights, we used molecular phenotyping by RNA-seq to quantify the transcriptome of A549 cells perturbed by CHiLL1 ASOs(72). CHiLL1 expression in control cells was 8.3 TPM (transcripts per million), equivalent to -4 molecules per cell and consistent with FISH(73). RNA-seq confirmed ASO knockdown efficiency (Figures $6 \mathrm{~d}$ and S6a), and resulting transcriptome changes were highly correlated between ASOs, indicating that the majority of effects arise via on- 
441 target perturbation of CHiLL1 (Figure 6e). Similar correlation was observed in H460 442 cells (Figure S6b). The generality of CHiLL1-dependent expression changes was 443 further confirmed by correlated expression changes between A549 and H460 (Figure 444 S6c).

$445 \quad$ We explored perturbed genes by enrichment analysis. Defining high-confidence target gene subsets from the intersection of both ASOs, we identified enriched KEGG terms(74) (Figures $6 f$ and S6d). These underscored disease relevance (e.g. "Nonsmall cell lung cancer"), and also implicated potential mechanistic pathways (MAPK, PI3K-Akt), and the high degree of concordance between the two cell backgrounds again supported the generality of CHiLL1 effects across KRAS ${ }^{+}$NSCLC cells.

Similar analysis of the Molecular Signatures Database (MSigDB)(75) implicated p53 and mTORC1 signalling (Figure S6e). Numerous transcription factor binding sites (TFBS) are enriched in changing genes, including ZBTB7A (in both A549 and H460)(76,77) (Figure S6f). Interestingly, ZBTB7A has been reported as both oncogene and tumour suppressor that regulates processes including apoptosis and glycolysis (78-81).

Amongst the cell-type independent enriched KEGG pathways was "Apoptosis" (Figure 6f). Supporting this, knockdown of CHiLL1, but not CHiLL2, resulted in a significant increase of early apoptotic cells (Figure $6 \mathrm{~g}$ ).

Turning to CHiLL2 (mean expression 2.5 TPM, 1 copies per cell), we observed effective knockdown and cell-type-independent effects using a single ASO (Figures 6h, 6i, and S6g). Gene enrichment analysis revealed partially overlapping terms with CHiLL1 (including p53 pathway, cholesterol homeostasis and epithelial to mesenchymal transition). Amongst the CHiLL2-specific terms, we noticed several related to cell cycle progression, including "G2-M checkpoint" (Figure 6j). Indeed, knockdown of CHiLL2, but not CHiLL1, led to an increase of cells in G2-phase (Figure 6k). CHiLL2 targets are also enriched for migration genes, and knockdown led to impaired cell migratory capability (Figure 6l).

Interestingly, we notice that CHiLL2 knockdown resulted in a significant upregulation of CHiLL1, but not vice versa, (Figure S6h), explaining the additive effect on cell viability observed with the CHiLL1 / CHiLL2 ASO cocktail (Figure 5g). 
bioRxiv preprint doi: $\mathrm{https} / /$ doi.org/10.1101/2021.10.19.464956; this version posted October 20, 2021. The copyright holder for this preprint (which was not certified by peer review) is the author/funder, who has granted bioRxiv a license to display the preprint in perpetuity. It is made available under aCC-BY-NC-ND 4.0 International license.

\section{Figure 6}

a) CHiLL2

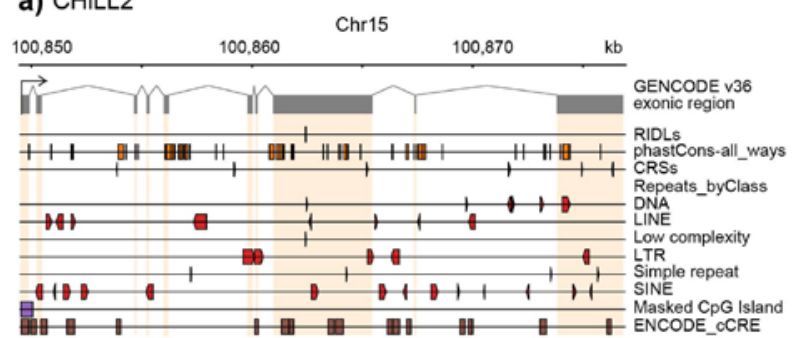

b) Fluoscence in-situ hybridisation (FISH)
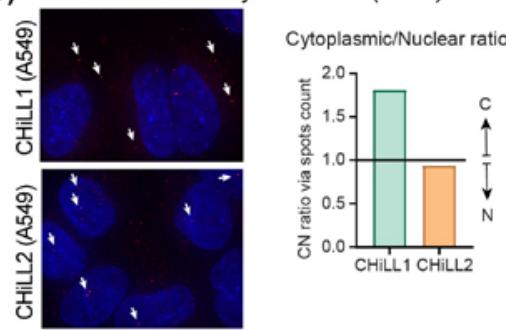

e) CHiLL1 ASOs (A549)

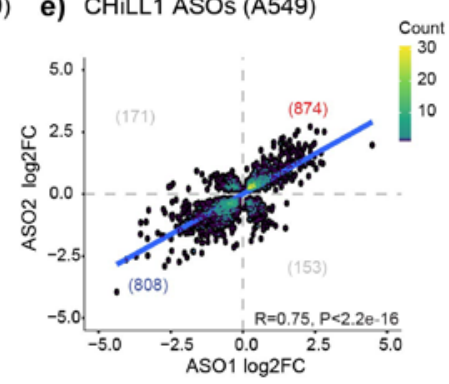

g) Apoptosis, 24h

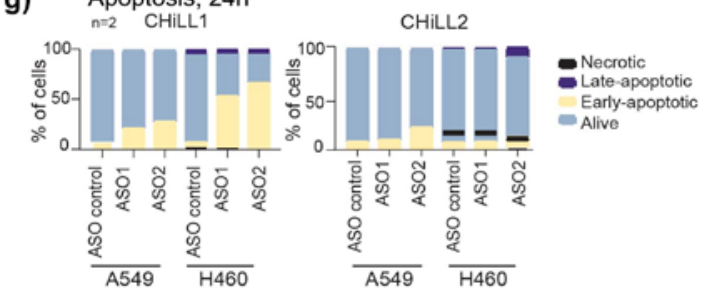

h) RNA-Seq CHiLL2 (A549) i) CHiLL2 ASO2 (A549/H460)
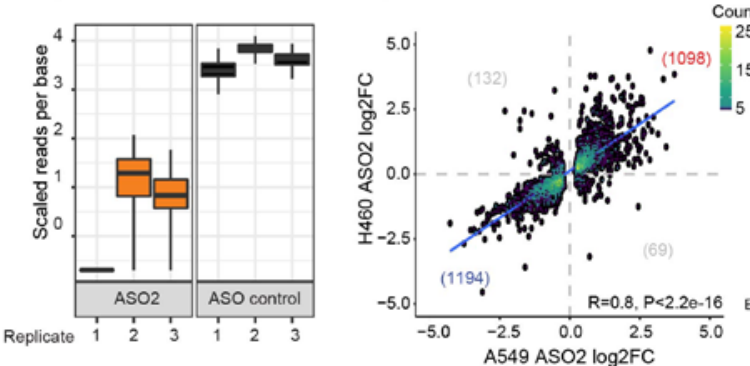

j) Enriched MSigDB terms CHiLL2

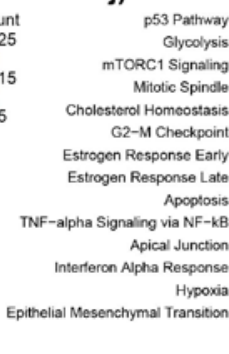

P53 Pathway
Glycolysis. Glycolysis

(1) Conse Early

$-k B$.

Sponse

Hypoxia

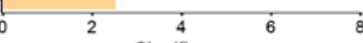

k) Cell cycle assay, 24h (A549) I) Migration (A549)

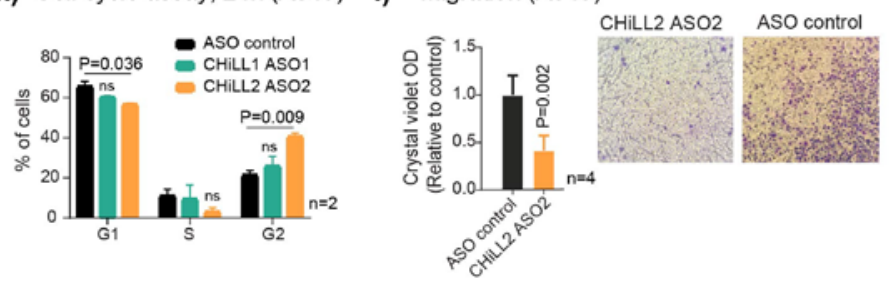


475 Figure 6. CHiLL1 and CHiLL2 drive distinct but overlapping oncogenic pathways. a)

476 Genomic elements in CHiLL2 exons (grey rectangles) and introns. Strand is indicated by

477 element direction, where appropriate. Plot was generated with ezTracks(82). b) Confocal

478 microscopy images of RNA-FISH performed with CHiLL1 and CHiLL2 probe sets in A549 cells.

479 Selected IncRNA foci are arrowed. Nuclear/Cytoplasmic (N/C) quantification of CHiLL 1\&2. c)

480 Ratio of concentrations of indicated RNAs as measured by RT-qPCR in nuclear/cytoplasmic

481 fractions of A549 cells. MALAT1 and GAPDH are used as nuclear and cytosolic controls,

482 respectively. d) Expression of CHiLL1 as quantified in the three RNA-seq replicates from A549

483 RNA. The $y$-axis represents the normalized expression (counts) per nucleotide and the

484 boxplots show the variance of inference using bootstraps generated by Kallisto. e) Fold

485 change in gene expression in response to CHiLL1 knockdown by ASO1 and ASO2 in A549

486 cells. Statistical significance: Pearson correlation coefficient. Trendline depicts regression line.

487 Numbers indicate genes in each quadrant. f) Statistical enrichment of KEGG pathways

488 amongst DEGs resulting from CHiLL1 knockdown. Genes significantly affected in common by

489 ASO1 and ASO2 were included, for each cell line. Cancer-relevant pathways that are

490 significant for both cell lines are highlighted in green. Statistical significance: Pearson

491 correlation coefficient. g) Annexin- $\mathrm{V}$ apoptosis assay $24 \mathrm{~h}$ after transfection with ASOs

492 targeting CHiLL1 (left) and CHiLL2 (right). h) As for C, for CHiLL2. i) As for D, but comparing

493 knockdown of CHiLL2 with the same ASO in A549 and H460 cells $(P=2.2 e-16 ; R=0.8$;

494 statistical significance: Pearson correlation coefficient). j) MSigDB term enrichment

495 significance for differentially-expressed genes in common between A549 and H460 cells. The

496 most significant terms are shown. y-axis: Adjusted P-value (q-value). k) Cell cycle assay

497 results after 24h upon knock-down of CHiLL1 and CHiLL2 in A549. ( $\mathrm{n}=2$ biological replicates,

498 error bars: standard deviation; statistical significance: two-tailed Student's $t$ test) l) Cell

499 migration across transwell supports in A549 cells. The crystal violet quantification is

500 normalised to non-targeting ASO ( $\mathrm{n}=4$ biological replicates, error bars: standard deviation;

501 statistical significance: one-tailed Student's $t$ test). 


\section{Discussion}

We have mapped the functional IncRNA landscape across hallmarks and cell backgrounds in the most common KRAS ${ }^{+}$subtype of NSCLC. This led us to promising therapeutic targets with pleiotropic roles across a range of 2- and 3-dimensional models from primary and metastatic tumours.

Pooled CRISPR screening is emerging as a foundation for therapeutic target identification, thanks to its practicality and versatility (83). It avoids the investment and expertise required for arrayed screening(84), and delivers improved perturbation and on-target rates compared to shRNA(35). By directly identifying IncRNAs via their celllevel function, it represents a welcome addition to widely-used, indirect evidence like survival, mutation, differential expression or evolutionary conservation $(85,86)$. It was encouraging to observe concordance between these signatures and screen hits. Nonetheless, key barriers to entry remain, notably the lack of available screening libraries, making the libDECKO-NSCLC1 library a valuable resource for future discovery.

Through its integrative strategy, this work sets new standards. Previous studies typically screened a single cell line with a single hallmark (often proliferation) and in a single format (often drop-out)(18,20,87) . Internal benchmarking here highlighted the risks of this approach, in identifying hits whose activity is specific to that cell background alone. We mitigated this with parallel screens in distinct but matched cell backgrounds, and resulting hits could be validated in several additional models and mutational subtypes. To identify pleiotropic hits, we performed parallel screens in multiple phenotypic dimensions and both positive and negative formats. The resulting challenge of integrating diverse screen data was solved by developing the simple yet robust TPP pipeline that balances effect size and significance. Overall, the combination of multiple screens with TPP yielded improved performance compared to conventional approaches.

The result is a unique functional panorama of IncRNAs in a single cancer type. Given the paucity of global-level functional IncRNA maps $(18,88)$, this dataset represents an invaluable resource for understanding both the basic biology of IncRNAs and their roles in cancer. Overall, our data implicate approximately $6 \%$ of IncRNAs with cell-level functions, comparable to Liu's and Zhu's estimates $(18,40)$. The 
conceptual and experimental configuration will have a broad application for other diseases and biological systems.

This resource enabled us to narrow down ten IncRNAs for ASO development, from which we identified a pair of oncogenic IncRNAs, CHiLL 1 \&2 with particularly promising characteristics as therapeutic targets. Firstly, replication experiments using distinct ASO sequences and in different cell backgrounds strong suggested that observed phenotypic and molecular effects occur on-target (via the intended IncRNA)(89). Second, ASOs were effective in both monolayer and three-dimensional $\mathrm{KRAS}^{+}$NSCLC backgrounds, in addition to several EGFR-mutant cell lines, raising hope for a more general utility. Future efforts will be required to further refine ASO sequences and chemistry, and to effectively deliver them in vivo. Third, those phenotypic effects were diminished in non-transformed cells, pointing to reduced nonspecific toxicity in vivo. This raises hopes for reduced toxicity in healthy cells, allowing not only higher doses, but also combination therapies to suppress therapy resistance(90). Finally, CHiLL1 or 2 are detected in the majority of KRAS ${ }^{+}$NSCLC tumours, suggesting the majority of patients might benefit from eventual treatment.

Mechanistically, the concordance of CRISPR and ASO phenotypes indicates that both genes act via an RNA transcript, or at least the production thereof $(56,91)$. Both have profound effects on the cellular transcriptome, affecting hundreds of target genes that converge on many shared, oncogenic pathways, which yielded experimentally verifiable predictions. Interestingly, however, these effects are mediated by very different immediate molecular mechanisms, as evidenced by their distinct subcellular localisation, non-overlapping target genes, and the fact that mixing their ASOs yielded greater than additive effects.

We have shown how ASO cocktails boosted efficacy without increasing toxicity, compared to equal doses of single ASOs. Our findings open the possibility of using either fixed cocktails or cocktails tailored specifically to a patient's tumour transcriptome, for potent, enduring, low-toxicity and personalised cancer treatment.

Nonetheless several issues remain to be addressed in future. It is likely that we overlooked many valuable IncRNA targets, due to the relative inefficiency of CRISPRdeletion as a perturbation compared to ORF mutation(92), and also due to the ongoing incompleteness of IncRNA annotation(93). We here screened in two monolayer cell backgrounds, however future screens should be performed in parallel across the widest panel of mutationally-matched 2- and 3-dimensional models(94). Finally, our 
bioRxiv preprint doi: https://doi.org/10.1101/2021.10.19.464956; this version posted October 20, 2021. The copyright holder for this preprint (which was not certified by peer review) is the author/funder, who has granted bioRxiv a license to display the preprint in perpetuity. It is made available under aCC-BY-NC-ND 4.0 International license.

568 screens discovered scores of IncRNAs that could not be followed up here and 569 hopefully will provide a fertile source of new targets in the future.

570 


\section{Additional information:}

572

573

574

575

576

577

578

579

580

581

582

583

584

585

586

587

588

589

590

591

592

593

594

595

596

597

598

599

600

601

\section{Acknowledgements}

We thank members of the GOLD Lab, including Joana Carlevaro-Fita, Núria Bosch-Guiteras, Michela Coan, Antonio Tarruell and Tina Uroda for insightful discussions. We also thank Roderic Guigó (CRG Barcelona) for insightful discussion. Thomas Marti and Renwang Peng (DMBR) generously donated cell lines and advice on functional assays. We thank Basak Ginsbourger (DBMR) for administrative support, and Willy Hofstetter and Patrick Furer (DBMR) for logistical support. All computation was performed on the Bern Interfaculty Bioinformatics Unit computing cluster maintained by Rémy Bruggmann and Pierre Berthier.

\section{Author contributions}

R.E., T.P., and R.J. conceived and designed the experiment procedure and performed data analysis and its interpretation. D.F.M developed the TPP pipeline and performed most of the bioinformatic analysis C.P. Designed the 'libDECKONSCLC1' with the help of S.H. P.C. Analyzed the RNA-seq data. S.F. and M.R. Established the patients-derived organoids. P.S., AK, G.B. and J.S. generated the stably-expressing Cas9 cell line lines and helped with the validation. E.S.W., I.M., and P.C.M. validated the results in additional cell lines. D.H. performed the analysis on the FISH images. L.Z. and X.W. performed the survival analysis from TCGA data. A.V. provided the set of known cancer genes in NSCLC. A.A., H.A.G., P.P.M. and A.L. contributed to the bioinformatic analysis. I.C. prepared the libraries for the NGS sequencing. S. H., C.R., and A.O. provided key inputs and tools. T.P., R.E. and R. J. wrote the manuscript with input from all the authors.

\section{Competing interests}

The authors declare no competing interests.

\section{Availability of data and material}

The data generated during this study will be available within few days in the Gene Expression Omnibus repository (GEO).

\section{Financial support}

This work was funded by the Swiss National Science Foundation through the National Center of Competence in Research (NCCR) 'RNA \& Disease' and Sinergia 
602 programme (173738), by the Medical Faculty of the University and University

603 Hospital of Bern, by the Helmut Horten Stiftung, by the Scherbarth Foundation, and

604 the Swiss Cancer Research Foundation (4534-08-2018). RJ was also supported by

605 Science Foundation Ireland through the Future Research Leaders programme

606 (18/FRL/6194). IM and ESW were funded by Tumor Microenvironment (TME)

607 CoBRE Grant (NIH/NIGMS P20GM121322), West Virginia IDeA-CTR (NIH/NIGMS

608 2U54 GM104942-03), National Science Foundation (NSF/1920920, NSF/1761792),

609 West Virginia IDeA Network of Biomedical Research Excellence (WV-INBRE)

610 (NIH/NIGMS P20GM103434). AA was supported by the Spanish Ministry of Science,

611 Innovation and Universities (FPU17/00067) and by an EMBO Short-Term

612 Fellowship. PPM's laboratory is supported by the Spanish Association Against

613 Cancer (LAB-AECC-2018) and by the Ministry of Economy of Spain (SAF2015-

614 67919-R).

615 Abbreviations

616 ASO: Antisense oligonucleotide

617 CRISPR: Clustered regularly interspaced short palindromic repeats

618 CHiLL: Cancer Hallmark in Lung LncRNA

619 DECKO: Dual excision CRISPR knock-out

620 FDR: False Discovery Rate

621

FISH: Fluorescence in situ hybridisation

622

FPKM: Fragments per kilobase of exon per million mapped fragments

623

KEGG: Kyoto Encyclopedia of Genes and Genomes

624

KO: Knock-Out

625

KRAS: Kirsten rat sarcoma virus

626

LNA: Locked Nucleic Acid

627

LncRNA: Long non-coding RNA

628

MOI: Multiplicity of infection

629

NGS: Next-Generation Sequencing

630

NSCLC: Non small cell lung cancer

631

ORF: Open Reading Frame

632

PCR: Polymerase Chain Reaction

633

pgRNA: paired guide RNAs

634

qPCR: quantitative Polymerase Chain Reaction 
RNA-seq: RNA-sequencing

636

RRA: Robust Rank Aggregation

637

TCGA: The Cancer Genome Atlas

638

TFBS: Transcription factor binding sites

639

TPM: Transcripts per million

640

TPP: Target prioritisation pipeline

641

TSS: Transcriptional Start Site 


\section{Cell lines and culture}

HEK293T, A549, H460, H441, CCD-16Lu cell lines were a kind gift by the groups were provided by the group of Ronald Dijkmanthe (Institute of Virology and Immunology, University of Bern). HBEC3-KT bronchial epithelial human cells were purchased from the American Type Culture Collection (ATCC; http://www.atcc.org). All the cell lines were authenticated using Short Tandem Repeat (STR) profiling (Microsynth Cell Line Typing) and tested negative for mycoplasma contamination.

A549 and HEK293T cells were maintained DMEM, MRC-5 in EMEM, NCl-H460, H441, and CCD-16Lu in RPMI-1640 medium, all supplemented with 10\% Fetal Bovine Serum, 1\% L-Glutamine, 1\% Penicillin-Streptomycin. HBEC3-KT were maintained in Airway Epithelial Cell Basal Medium (ATCC ${ }^{2}$, cat. no. PCS-300-030) supplemented with Bronchial Epithelial Cell Growth Kit (ATCC ${ }^{8}$, cat. no. PCS-300-040).

All cells were passaged every $2-3$ days and maintained at $37^{\circ} \mathrm{C}$ in a humid atmosphere with 5\% CO2.

659

\section{Lentiviral infection and stable cell line production}

The plasmids used in this paper are listed in File S4. Lentivirus production was carried out by co-transfecting HEK293T cells with $12.5 \mu \mathrm{g}$ of Cas9 plasmid with blasticidin resistance (Addgene, cat. no. 52962), $7.5 \mu \mathrm{g}$ psPAX2 plasmid and $4 \mu \mathrm{g}$ the packaging pVsVg plasmids, using Lipofectamine2000. 24h before the transfection, 2.5e6 HEK293T cells were seeded in a $10 \mathrm{~cm}$ dish coated with Poly-L-Lysine (Sigma, cat. no. P4832) (diluted 1:5 in 1X PBS). The supernatant containing viral particles was harvested $24 \mathrm{~h}, 48 \mathrm{~h}$ and $72 \mathrm{~h}$ after transfection. Viral particles were then concentrated 100-fold by adding 1 volume of cold PEG-it Virus Precipitation Solution (BioCat, cat. no. LV810A-1-SBI) to every four volumes of supernatant. After $12 \mathrm{~h}$ at $4^{\circ} \mathrm{C}$, the supernatant/PEG-it mixture was centrifuged at $1,500 \times \mathrm{g}$ for $30 \mathrm{~min}$ at $4^{\circ} \mathrm{C}$, resuspended in $1 \mathrm{X} \mathrm{PBS}$, and stored at $-80^{\circ} \mathrm{C}$ till use.

For the generation of stable Cas9-expressing cell lines, A549 and H460 were incubated for $24 \mathrm{~h}$ with culture medium containing concentrated viral preparation 
674

675

676

677

678

679

680

681

682

683

684

685

686

687

688

689

690

691

692

693

694

695

696

697

698

699

700

701

702

703

704

705

carrying pLentiCas9-T2A-BFP and $8 \mu \mathrm{g} / \mathrm{ml}$ Polybrene. Infected cells were selected for at least five days with blasticidin $(8 \mu \mathrm{g} / \mathrm{mL})$ and then were FACS-sorted two times, so as to have at least $60 \%$ BFP-positive cells.

\section{Design and cloning of DECKO plasmids and lentiviral production}

For the design and cloning of DECKO plasmids, we used our previouslydescribed protocol(23,95) (http://crispeta.crg.eu/).

To produce lentivirus carrying the pDECKO plasmid, we followed the same protocol. After infection with pDECKO plasmid-carrying viruses, cells were selected with puromycin $(\mu \mathrm{g} / \mathrm{mL})$ for at least three days.

\section{Library design}

We downloaded GTF-format annotations from the following sources: i) GENCODE annotation release 19 (GRCh37) from gencodegenes.org; ii) BIGTranscriptome annotation(28) from http://big.hanyang.ac.kr/CASOL/ I; iii) FANTOM CAT(10). We also generated a novel transcriptome assembly of A549 RNAseq(30,31) using StringTie(96), version 1.3.

All IncRNAs were filtered thus: First, those with transcription start sites (TSS) $<2 \mathrm{~kb}$ from any protein-coding gene exon were removed. Second, expression was calculated with RSEM v1.3 (97), and transcripts with FPKM $<0.1$ were removed. Remaining TSS within 300 bp were clustered into a single TSS. TSS were intersected with ENCODE evidence source specific to A549 cells: CAGE, DNAse I hypersensitivity sites and ChromHMM marks: Active TSS, Flanking TSS, Promoter Downstream TSS, Flanking TSS Downstream, Genic enhancer1, Genic enhancer2, Active Enhancer 1, Active Enhancer 2, Weak Enhancer and Bivalent-Poised TSS $(30,31,98)$. Candidates were prioritized by the number of evidence sources.

We designed neutral control pgRNAs in genomic regions not expected to affect cell phenotype. We retrieved 10 regions in the AAVS1 gene loci from the publication of Zhu and colleagues (99). To this set we added a set of 65 randomly selected intergenic regions (>10 kb distant from nearest gene annotation) and 25 intronic regions (for introns $>5 \mathrm{~kb}$ in length). Moreover, 53 positive (promoting cell growth) and 50 negative (opposing cell growth) protein-coding gene (PCG) controls, with known 
roles promoting/opposing cancer cell growth and cisplatin resistance were added. These were manually selected from literature and retrieved from the paper of Zhu and colleagues(99). The complete list of genes contained in the library is available in File S1.

10 unique pgRNAs were generated for each candidate region with CRISPETa(95) using the following parameters: -eu 0 -ed 0 -du 1000 -dd 1000 -si 0.2 -t $0,0,0, x, x-v 0.4$-c DECKO. For the candidates where $<10$ pgRNAs could be identified, the parameters were subsequently loosened until 10 were reached: in the second round one off-target with 3 mismatches was allowed; in the third round the designs region was repeatedly increased in size (summary in File S5, Table 2).

The final library design comprised 12,000 unique sequences of length 165/166 $\mathrm{bp}$, with overhangs compatible with cloning into the pDECKO plasmid $(23,95)$. The median distance between the pgRNAs is shown in Figure S1d.

\section{Library cloning}

Library was synthesized as single stranded oligonucleotides by Twist Bioscience (USA), and upon arrival resuspended in nuclease-free low Tris-EDTA (TE) buffer (10 $\mathrm{mM}$ Tris- $\mathrm{HCl}, \mathrm{pH} 8.0$ and $0.1 \mathrm{mM}$ EDTA) to a final concentration of $10 \mathrm{ng} / \mu \mathrm{l}$. This was PCR amplified using the Oligo-Fw: 5'-ATCTTGTGGAAAGGACGAAA-3' and OligoRev: GCCTTATTTTAACTTGCTATTTC (PCR mix listed in File S5, Table 3) with the following conditions: $95^{\circ} \mathrm{C} \times 1 \mathrm{~min} ; 10$ cycles of $\left(95^{\circ} \mathrm{C} \times 1 \mathrm{~min}, 53^{\circ} \mathrm{C} \times 20 \mathrm{sec}, 72^{\circ} \mathrm{C} \times\right.$ $1 \mathrm{~min}) ; 72^{\circ} \mathrm{C} \times 10 \mathrm{~min}$. The amplification product was purified using the QIAquick PCR Purification Kit (Qiagen, cat. no. 28104) according to the manufacturer's instructions. The correct amplicon size was checked on a 2\% agarose gel at 100 for $40 \mathrm{~min}$.

The steps of cloning follow the low-throughput protocol described in (100). In the first step, the pDECKO_mCherry plasmid was digested following the conditions listed in File S5, Table 4. The amplified library was inserted into the digested plasmid, using Gibson Assembly mix (obtained from 'Biomolecular Screening \& Protein Technologies' Unit at CRG, Barcelona) at $50^{\circ} \mathrm{C}$ for $1 \mathrm{~h}$ (200ng of pDECKO_mCherry plasmid, 20ng amplified library, $\mathrm{H} 2 \mathrm{O}$ up to $10 \mu \mathrm{l}, 10 \mu \mathrm{l}$ of Gibson mix $10 \mu \mathrm{l}) .1 \mu \mathrm{l}$ of the Gibson reaction was delivered to $25 \mu \mathrm{l}$ of electrocompetent EnduraTM cells (Lucigen, cat. no. 60242-2) using Gene Pulser ${ }^{\circledR} /$ MicroPulser ${ }^{\mathrm{TM}}$ Electroporation Cuvettes, $0.1 \mathrm{~cm}$ gap (Biorad, cat. no. 16520891). The library coverage of $66.7 X$ was estimated by 
counting the number of obtained bacterial colonies divided by the total number of different sequences in the designed library $(12,000)$. The intermediate plasmid obtained in this step contains the pgRNA variable sequences, but still lacks the constant part of the first sgRNA and the $\mathrm{H} 1$ promoter (Figure S1b)(23).

In the second step of cloning, the intermediate plasmid was digested by Bmsbl enzyme (ThermoFisher, cat. no ER0451). After purification, the constant insert was assembled by ligation, by using PAGE purified and 5' phosphorylated long oligos (File S5, Table 5), as explained in(100). Afterwards, $5 \mu \mathrm{l}$ of the ligation product was transformed and used for the electroporation of electrocompetent Endura ${ }^{\mathrm{TM}}$ cells as described above. Clones were tested by colony PCR and by Sanger sequencing using primer sequences found in File S5, Table 6. The PCR conditions are listed in File S5, Table 7 . The overall library quality was evaluated by NGS sequencing. Briefly, the plasmid containing the pgRNAs was amplified by PCR (primers listed in File S5, Table 8), purified using Agencourt AMPure XP beads (Beckman Coulter, cat. no. A63880), according to the manufacturer's protocol. The purified product was sequenced by Illumina at a depth of 20M PE125 reads. The reads were aligned to the pgRNAs library and the read distribution of each pgRNA was determined using the Ineq package in R (version 3.5.3) to calculate both the Lorenz-curve and Gini-coefficient (Figure S1c).

\section{Lentiviral titer calculation and lentiviral infection}

To achieve the desired multiplicity of infection (MOI) of $0.3-0.4$, a titration experiment in A549 and $\mathrm{H} 460$ cells was performed. $2 \mathrm{e} 6$ cells were plated in each well of a 12-well plate and supplemented with $8 \mu \mathrm{g} / \mathrm{ml}$ polybrene. Each well was treated with virus ranging from 2.5 and $50 \mu \mathrm{l}$ and transduced via spin-infection as previously described (101). After centrifugation, the media was replaced with complete fresh media without polybrene and incubated overnight. The following day, cells were counted and each well was split in two equal aliquots, of which one was treated with $2 \mu \mathrm{g} / \mathrm{ml}$ puromycin. After $72 \mathrm{~h}$, the $\mathrm{MOI}$ was calculated by dividing the number of surviving cells in the puromycin well, by the number in the puromycin-free well. The $\mathrm{MOI}$ of 0.3 was used for all screening experiments. For large-scale screens, $120 \mathrm{M}$ cells were seeded in 12-well plates with a density of $2 \mathrm{M}$ per well for spin-infection. The following day, cells were pooled together and fresh puromycin-containing $(2 \mu \mathrm{g} / \mathrm{ml})$ 
771

medium was added. Puromycin selection was maintained for six days until phenotypic screens began.

\section{CRISPR screens}

One week after infection (Timepoint 0 or T0), cells were counted and the reference sample was collected (T0,16M cells corresponding to a library coverage $>1,000 x$ ). For all screens, cells were cultured in $150 \mathrm{~mm}$ culture-treated dishes and passaged every 2-3 days.

Proliferation. Drop-out screens: at T0 16M of cells were plated and passaged so as to maintain a coverage $>1,000 X$ (defined as the number of cells divided by the number of unique library sequences). Cells were harvested at 14 and 21 days for gDNA extraction. CFSE screens: At T7, 16M cells were seeded and starved for $24 \mathrm{~h}$ with media lacking FBS. Then cells were stained using CellTrace ${ }^{\mathrm{TM}}$ CFSE Cell Proliferation Kit (ThermoFisher, cat. no. C34570) following the manufacturer's instructions. One aliquot of stained cells was immediately analyzed by flow cytometry, while the rest were plated with normal media. Five days later (T5), cells were sorted into two populations: $20 \%$ brightest (slow-growing) and 20\% least bright (fastgrowing). The two populations were plated separately and, five days later (T10) subjected to another round of staining and sorting.

Cisplatin screen. Optimal cisplatin working concentrations were established via dose response (Figure S2d) and cell doubling time (Figure S2e). In the dose response, 3,000 A549 and $\mathrm{H} 460$ cells were plated in 96-well plates and treated with a range of cisplatin concentrations. After 72 h, CellTiter-Glo 2.0 (Promega, cat. no. G9242) was added to the media (1:1), and luminescence was recorded. For the cell doubling time, $1 \mathrm{M}$ cells were plated in $10 \mathrm{~cm}$ plates. Different cisplatin concentrations were added at indicated concentrations, and living cells counted every 2-3 days up to 14 days. Cisplatin survival screen: $48 \mathrm{M}$ and $96 \mathrm{M}$ cells were plated at T0 and treated with 6.5 $\mu \mathrm{M}$ and $25 \mu \mathrm{M}$ of Cisplatin for A549 cells and $2 \mu \mathrm{M}$ and $10 \mu \mathrm{M}$ for H460 cells, corresponding to IC30 and IC80, respectively. Cell pellets were collected after 14 and 21 days. The death screen was carried out as follows: 144M cells were seeded and treated with cisplatin at $2 \mu \mathrm{M}$ and $1 \mu \mathrm{M}$ (IC20) for A549 and H460, respectively (Figure S2d). Every $24 \mathrm{~h}$, for five days, floating (dead) cells were collected and pooled together for gDNA extraction. 
803

804

805

806

807

808

809

810

811

812

813

814

815

816

817

818

819

820

821

822

823

824

825

826

827

828

829

830

831

832

833

Migration screen. To test the optimal conditions, the following set-up experiment was performed. $0.5 \mathrm{M}$ A549 cells/well were seeded in 5 Boyden chambers (Corning, PC Membrane, $8.0 \mu \mathrm{m}, 6.5 \mathrm{~mm}$, cat. no. 3422-COR). Each migration assay was stopped at a different timepoint (ranging from $5 \mathrm{~h}$ up to $48 \mathrm{~h}$; Figure S2g). $48 \mathrm{~h}$ was selected as timepoint for the following experiment. At T0 infected cells ( 16M) were divided and seeded in the upper part of 32 transwell inserts $(0.5 \mathrm{M}$ cells/transwell). The upper part of transwell inserts was filled with media lacking FBS, the lower part with media containing $10 \%$ FBS. After $48 \mathrm{~h}$ cells in the upper part of the chamber (impaired migration) and lower part (accelerated migration) (Figure 2c) were trypsinized and plated separately for $48 \mathrm{~h}$, after this time, cells were counted and collected for gDNA extraction. Control cells that did not undergo the migration assay were harvested at the same time as a reference population.

\section{Genomic DNA preparation and sequencing}

Genomic DNA (gDNA) was isolated using the Blood \& Cell Culture DNA Midi (5e6-3e07 cells) (Qiagen, cat. no. 13343), or Mini ( $<5 \mathrm{e} 6 \mathrm{cells}$ ) Kits (Qiagen, cat. no. 13323) as per the manufacturer's instructions. The gDNA concentrations were quantified by Nanodrop.

For PCR amplification, gDNA was divided into $100 \mu \mathrm{l}$ reactions such that each well had at most $4 \mu \mathrm{g}$ of gDNA. Each well consisted of $66.5 \mu \mathrm{l}$ gDNA plus water, $23.5 \mu \mathrm{l}$ PCR master mix ( $20 \mu \mathrm{l}$ Buffer 5X, $2 \mu \mathrm{l}$ dNTPs $10 \mu \mathrm{M}, 1.5 \mu \mathrm{l}$ GoTaq; Promega, cat. no. $\mathrm{M} 3001$ ), and $5 \mu \mathrm{l}$ of Forward universal primer, and $5 \mu \mathrm{l}$ of a uniquely barcoded P7 primer (both stock at $10 \mu \mathrm{M}$ concentration). PCR cycling conditions: an initial $2 \mathrm{~min}$ at $95^{\circ} \mathrm{C}$; followed by $30 \mathrm{~s}$ at $95^{\circ} \mathrm{C}, 40 \mathrm{~s}$ at $60^{\circ} \mathrm{C}, 1 \mathrm{~min}$ at $72^{\circ} \mathrm{C}$, for 22 cycles; and a final 5 min extension at $72^{\circ} \mathrm{C}$. NGS primers are listed in File S5, Table 9 and Table 10. PCR products were purified with Agencourt AMPure XP SPRI beads according to manufacturer's instructions (Beckman Coulter, cat. no. A63880). Purified PCR products were quantified using the Qubit ${ }^{\mathrm{TM}}$ dsDNA HS Assay Kit (ThermoFisher, cat. no. Q32854). Samples were sequenced on a HiSeq2000 (Illumina) with paired-end $150 \mathrm{bp}$ reads at coverage of $40 \mathrm{M}$ reads/sample.

\section{Screen hit identification and prioritisation}


The raw sequencing reads from individual screens were analyzed by using CASPR(102). After the mapping step, the obtained counts per million (cpm) for each pgRNA were filtered to remove sequences with $3>c p m>666$. Low scoring guides were removed by GuideScan(103), and a batch effect correction was applied using MageckFlute(104). After all the corrections, the table count was provided to CASPR to calculate log2-Fold Change and FDR corrected P-values at a target level.

To integrate multiple screens an integrative target prioritisation pipeline (TPP) was designed, applying two different approaches in parallel: the Robust Rank Aggregation (RRA)(105) to compute a ranking based on the effect size (CASPR log2FC) across screens; and an empirical adaptation of Brown's method (EBM)(106) to combine the significance values (CASPR P-value) of each candidate across screens. The RRA-scores were converted to exact P-values using the rho-score correction from the same $\mathrm{R}$ package. Subsequently, the harmonic mean P-value (HMP)(107) was calculated using the two significance scores from RRA and EBM. These P-values were corrected for multiple hypothesis testing using the Benjamini \& Hochberg method, and a cutoff of FDR $<0.2$ was used to define hits. The code is available at https://github.com/RescueGum/TargetPP.

Enrichment scores and nominal P-values (GSEA simulation, $n=10,000$ ) of positive and neutral control genes were used as indication for the quality of the ranking, as well as fraction of detected genes previously linked to lung cancer(11). Positive and neutral control genes were also used as "true positives/false negatives" and "false positives/true negatives" respectively to calculate ROC curves and associated statistical metrics.

\section{Public RNA-sequencing data}

$101 \mathrm{KRAS}^{+}$LUAD RNA-seq samples were downloaded from TCGA (gdc.cancer.gov), applying the following filters: Adenocarcinoma - not treated - KRAS mutated, and the expression of target genes was estimated using HTSeq(108). Another independent cohort of LUAD RNA-seq ex-vivo data, containing 87 tumour and 77 adjacent normal tissue samples, was obtained from the TANRIC $(60,109)$.

\section{PCR amplification from genomic DNA}


gDNA was extracted with GeneJET Genomic DNA Purification Kit (ThermoFisher, cat. no. K0702) from pDECKO-transduced A549-Cas9-expressing cells. The PCR was done with primers flanking the deleted region (File S5, Table 11) as shown in Figure 1F, using the Phusion ${ }^{\mathrm{TM}}$ High-Fidelity DNA Polymerase (2 $\mathrm{U} / \mu \mathrm{l}$ ) (ThermoFisher, cat. no. F-530S). The product was run on a 1\% agarose gel.

\section{Competition assay}

A549 cells were infected with DECKO lentiviruses expressing fluorescent proteins. Viruses expressing control pgRNAs targeting AAVS1 also expressed GFP protein (pgRNAs-AASV1-GFP+), while the pgRNAs targeting candidate IncRNAs expressed mCherry. After infection, and seven days of puromycin $(2 \mu \mathrm{g} / \mathrm{ml})$ selection, GFP and mCherry cells were mixed 1:1 in a six-well plate (150,000 cells). Cell counts were analyzed by LSR II SORP instrument (BD Biosciences) and analyzed by FlowJo software (Treestar).

881

882

883

884

885

886

887

888

889

890

891

892

893

894

895

896

897

\section{Patient-derived xenograft organoids}

The $\mathrm{KRAS}^{+}$patient-derived organoid BE874 was derived in the following way. Small pieces $\left(\sim 1-2 \mathrm{~cm}^{3}\right)$ of lung cancer tissue (provided by the Institute of Pathology, University of Bern) were taken from the surgically resected lung cancer specimen with patients' informed consent. Parts of the sample (pieces of around $5 \mathrm{~mm}$ ) were separated and implanted subcutaneously into the flanks of 6 weeks old NOD.CgPrkdcscidll2rgtm1Wjl/SzJ (NSG) mice (purchased from Charles River Laboratories) for cancer engraftment(110). After successful engraftment, tumour bearing mice were euthanized and tumours were resected. Single cells were isolated through mechanical and enzymatic tissue disruption for generation of BE874 organoids. Genotyping of BE874 organoids was performed at the Institute of Pathology, University of Bern, using KRAS targeted sanger sequencing. KRAS c.34G $>\mathrm{T}$ (p.Gly12Cys) mutation was detected in both BE874 organoids and the corresponding primary cancer.

NSG mice were housed under specific pathogen-free conditions in isolated ventilated cages on a regular 12-hour/12-hour cycle of light and dark. Mice were fed ad libitum, and were regularly monitored for pathogens. Mouse experiments were 
898

899

900

901

902

903

904

905

906

907

908

909

910

911

912

913

914

915

916

917

918

919

920

921

922

923

924

925

926

927

928

licensed by the Canton of Bern and were performed in compliance with Swiss Federal legislation.

\section{Antisense oligonucleotides}

Locked nucleic acid ASOs were designed using the Qiagen custom LNA oligonucleotides designer (www.qiagen.com). Per each target, we designed from 3 to 5 different ASOs. The day of the transfection, 300,000 cells were counted and plated on a 6-well plate. ASOs were transfected into the cells still in suspension, using Lipofectamine3000 (ThermoFisher, cat. no. L3000015) with final $25 \mathrm{nM}$ in $2 \mathrm{ml}$ media for A549, H460, NCl-H441, and MRC5-CV1 and $10 \mathrm{nM}$ in $2 \mathrm{ml}$ for HBEC3-KT and CCD-16LU, following the manufacturer's instructions.

For cocktail experiments the final concentration of the ASOs mix was kept at 25 $\mathrm{nM}$. The media was refreshed $24 \mathrm{~h}$ post transfection and cells were harvested to check the efficiency of gene knockdown or sub-cultured for cell viability experiments. The ASOs target sequences are listed in File S5, Table 1. We checked ASOs penetration in cells by means of the 5'-FAM-labeled control ASO A provided by Qiagen (Figure S5f).

\section{D cell viability assay}

Cell viability assay was carried out in 2D cell lines by using CellTiter-Glo 2.0 (Promega, cat. no. G9242). The assays were performed according to the corresponding manufacturer's protocol. $24 \mathrm{~h}$ after the transfection, $\mathrm{A} 549, \mathrm{H} 460, \mathrm{NCl}-$ H441, H1975, H157, WVU-Ma-0005A, H820 and H1650 cells were harvested, counted and 3,500 cells/well were seeded in triplicate in 96 well plates. For Mrc5-SV1, HBEC3KT and CCD-16LU 3,000, 3,500, and 1,000 cells/well were seeded, respectively. The number of viable cells was estimated after 24, 48, 72, 96 and/or $144 \mathrm{~h}$. The day of the measurement, a mix of 1:1 media and CellTiter-Glo was added to the plates and the luminescence was recorded with Tecan Infinite ${ }^{\circledR} 200$ Pro. Student's $t$ test was used to evaluate significance $(\mathrm{P}<0.05)$. 
$\mathrm{NCl}-\mathrm{H} 441$ cells were detached, counted, and 200,000 cells were plated in 24 well

930

931

932

933

934

935

936

937

938

939

940

941

942

943

944

945

946

947

948

949

950

951

952

953

954

955

956

957

958

959

960 plates. The ASO-Lipofectamine3000 mix was delivered to the cells in suspension as described above. After 24 hours, the cells are detached, counted and seeded onto 96well Black/Clear Round Bottom Ultra-Low Attachment Surface Spheroid Microplate (Corning, cat. no. 4520) in $20 \mu$ d domes of Matrigel@ Matrix GFR, LDEV-free (Corning, cat. no. 356231) and RPMI-1640 growth medium (1:1) with a density of 20,000 cells per dome. Matrigel containing the cells was allowed to solidify for an hour in the incubator at $37^{\circ} \mathrm{C}$ before adding DMEM-F12 (Sigma, cat. no. D6421) media on top of the wells $(40 \mu \mathrm{l}$ and $80 \mu \mathrm{l}$ for the wells intended to the first and second timepoint, respectively. The spheroids were allowed to grow in the incubator at $37^{\circ} \mathrm{C}$ in a humid atmosphere with $5 \% \mathrm{CO}$. After $4 \mathrm{~h}$ the number of viable cells in the 3D cell culture was recorded as time point 0 (T0), CellTiter-Glo ${ }^{\circledR}$ 3D Cell Viability Assay (Promega, cat. no. G9682) was added to the wells, following the manufacturer's instructions and the contents transferred into a Corning ${ }^{\circledR}$ 96-well Flat Clear Bottom White (Corning, cat. no. 3610) for the reading with the Tecan Infinite ${ }^{\circledR} 200$ Pro. After one week the measurement was repeated.

BE874 organoids were generated and expanded using a special lung cancer organoid (LCO) medium (File S5, Table 12).

BE874 organoids were transfected with ASOs as described for the NCl-H441. 24 $\mathrm{h}$ after transfection the cells were detached, counted and seeded onto Corning ${ }^{\circledR}$ 96well Flat Clear Bottom White (Corning, cat. no. 3610) in $20 \mu \mathrm{l}$ domes of LCO growth medium and Matrigel (1:1) with a density of 20,000 cells per dome. The Matrigelcontaining PDX-organoids was allowed to solidify for an hour in the incubator at $37^{\circ} \mathrm{C}$ before adding $80 \mu \mathrm{L}$ LCO growth media on top. The organoids were allowed to grow in the incubator at $37^{\circ} \mathrm{C}$ in a humid atmosphere with $5 \% \mathrm{CO} 2$. After $24 \mathrm{~h}, 100 \mu \mathrm{l}$ of CellTiter-Glo ${ }^{\circledR} 3 \mathrm{D}$ Cell Viability Assay (Promega cat. no. G9682) were added to the wells intended for the T0 and the luminescence was recorded with Tecan Infinite ${ }^{\circledR} 200$ Pro. After three days the $80 \mu \mathrm{l}$ of LCO media were added to the wells to keep them from drying out. After one week, the media was aspirated and replenished with fresh $80 \mu \mathrm{l}$, before proceeding with the measurement with CellTiter-Glo® ${ }^{\circledR}$ D.

\section{Apoptosis assay}


961

962

963

964

965

966

967

968

969

970

971

972

973

974

975

976

977

978

979

980

981

982

983

984

985

986

987

988

989

990

991

992

Annexin $\mathrm{V}$ and viability dye were used to detect early apoptotic and dead cells, respectively. $24 \mathrm{~h}$ after the transfection, cells were counted and 150,000 cells were resuspend in $100 \mu$ of $1 \mathrm{X}$ PBS. The viability dye (ThermoFisher, cat. no. 35111) was added $(1: 5,000)$ in $100 \mu$ l of 1 X PBS and cells incubated for 30 minutes at $4^{\circ} \mathrm{C}$. Cells were then washed once with 1 X PBS and re-suspend in $100 \mu \mathrm{l}$ of Annexin buffer PH 7, added PE Annexin (1:200; ThermoFisher, cat. no. L34960) and incubated 30 minutes at $4^{\circ} \mathrm{C}$. After a wash with 1 XPBS, cells were resuspended in $300 \mu$ l of Annexin buffer and underwent the flow analysis by using the LSR Fortessa instrument (BD Biosciences). Unstained cells were used as control.

\section{Cell cycle assay}

Cells were transfected with ASOs using Lipofectamine3000 according to the manufacturer's instructions. $24 \mathrm{~h}$ after, cells were harvested and fixed with $100 \mu \mathrm{l}$ of BD Cytofix/Cytoperm Fixation (BD Biosciences, cat. no. 51-2090KZ) for 30 minutes at room temperature. The cells were then washed with $200 \mu$ of 1 X BD Perm/Wash (BD Biosciences, cat. no. 51-2091KE) and resuspended in $100 \mu \mathrm{l}$ of $1 \mathrm{X}$ PBS. The K-i67 Antibody (ThermoFisher cat. no. 12-5698-82) was added (1:100) and incubated for 30 minutes at $4^{\circ} \mathrm{C}$. Wash again with $1 \mathrm{X} B \mathrm{~B}$ perm/wash and stain with DAPI (Roche, cat. no. 10236276001$)$ was added $(1: 10,000)$ in $100 \mu$ of $1 X$ PBS. Incubate 5 ' at room temperature and wash with $1 \mathrm{X}$ PBS. Acquire the data with the Fortessa flow cytometer. Data analysis performed using FlowJo, and the different cell cycle phases were determined according to the Dean-Jett Fox (DJF) model.

\section{Low-throughput migration assay}

Migration assay was performed as previously described(111). $24 \mathrm{~h}$ after ASOs transfection, A549 cells were counted and seeded in the upper part of Boyden chambers with the density of 35,000 cells/transwell. The upper part of transwell inserts was filled with media without FBS, while the lower part with media supplemented with $10 \%$ FBS to induce the directional movement of cells. After $24 \mathrm{~h}$ the cells were washed three times with 1 X PBS and stained using $300 \mu$ of crystal violet $1 \%$ for 30 minutes. Three washes with $1 \mathrm{X}$ PBS followed. The cells in the upper part of the membrane were removed by using a cotton swab. The chambers are left to dry overnight. The 
993

994

995

996

997

998

999

1000

1001

1002

1003

1004

1005

1006

1007

1008

1009

1010

1011

1012

1013

1014

1015

1016

1017

1018

1019

1020

1021

1022

1023

day after, the crystal violet was solubilized in 1X PBS containing 1\% SDS and the absorbance at $595 \mathrm{~nm}$ was recorded by using the Tecan Infinite ${ }^{\circledR} 200$ Pro.

\section{RNA isolation and qRT-PCR}

To purify total RNAs from cultured cells, a Quick-RNA ${ }^{\text {TM }}$ kit from ZymoResearch was used according to the manufacturer's protocol. RNAs were reverse transcribed to produce cDNAs by using the GoScript ${ }^{\mathrm{TM}}$ Reverse Transcription System Kit (Promega, cat. no. A5003). The cDNAs were then used for qPCR to evaluate gene expression, using the GoTaq ${ }^{\circledR}$ qPCR Master Mix kit (Promega, cat. no. A6002). The expression of HPRT1 was used as an internal control for normalization. All the primers are listed in File S5, Table 13.

\section{RNA-sequencing and analysis}

$24 \mathrm{~h}$ after ASO transfection, A549 and H460 cells were harvested and the total RNA was extracted as explained before and samples' quality was checked at Bioanalyzer. Libraries were prepared using the NEBNext ${ }^{\circledR}$ Ultra RNA Library Prep Kit and sequenced in paired-end 150 format to a depth of $30 \mathrm{M}$ reads/sample.

Transcript quantification was performed using Kallisto v0.46.0(112) against GENCODE v36(29). Gene level expression was inferred by aggregating the counts of the individual isoforms. Differential expression analysis was performed using Sleuth v0.30(113). Genes with a q-value $<0.2$ were considered significant. For CHiLL1, the genes that were significantly up- and down-regulated with two different ASO were selected. For CHiLL2, we selected the pool of common genes deregulated in A549 and $\mathrm{H} 460$.

Visualization of the results was produced in $\mathrm{R} 4.0 .0$ ( $\mathrm{R}$ : The $\mathrm{R}$ Project for Statistical Computing, n.d.) using ggplot2 package v3.3.2 (Ggplot2 - Elegant Graphics for Data Analysis | Hadley Wickham | Springer, n.d.). Functional enrichment analysis was performed through the enrichR package v2.1(114).

\section{Fluorescent In-Situ Hybridization (FISH) and cell fractionation}

FISH was performed on A549 cell lines, according to the Stellaris protocol (https://www.biosearchtech.com/support/resources/stellaris-protocols). For detection 
1024

1025

1026

1027

1028

1029

1030

1031

1032

1033

1034

1035

1036

1037

1038

1039

1040

1041

1042

1043

1044

1045

1046

1047

1048

1049

1050

1051

1052

1053

1054

of CHiLL $1 \& 2$ at a single-cell level, pools of 25 and 48 FISH probes respectively were designed using the Stellaris probe designer software (www.biosearchtech.com). Cells were grown on round coverslip slides (ThermoFisher, $18 \mathrm{~mm}$ ), fixed in $3.7 \%$ formaldehyde and permeabilized in ethanol 70\% overnight. Hybridization was carried out overnight at $37^{\circ} \mathrm{C}$ in hybridization buffer from Stellaris. Cells were counterstained with DAPI and visualized using the DeltaVision microscope.

Nuclear and cytoplasmic fractionation was carried out in A549 cells as described previously(71). The pipeline used to analyse the data was adapted from CellProfiler (115), and it is named 'SpeckleCounting'.

\section{ezTracks visualisation of RNA elements}

Genomic tracks were retrieved for the hg38 human genome assembly from their original publications: predicted neo-functionalised fragments of transposable elements, also known as RIDLs (repeat insertion domains of IncRNA) (71), RNA structures conserved in vertebrates (CRS) (116), and ENCODE candidate cisregulatory elements(117). In addition, the following tracks were downloaded from the UCSC Genome Browser(118): repeat-masked CpG islands, phastCons conserved elements in 7, 20, 30 and 100-way multiple alignments(119), and repeat families from the RepeatMasker annotation (Smit, AFA, Hubley, R \& Green, P. RepeatMasker Open-4.0. 2013-2015; http://www.repeatmasker.org).

The comprehensive gene annotations for CHiLL1 (ENSG00000253616) and CHiLL2 (ENSG00000272808 and ENSG00000232386) loci were extracted from the GENCODE v36 GTF file(29). Then, all the exons corresponding to each locus were collapsed into a meta-transcript and output as separate GTF files using BEDTools merge(120). Third, configuration files for each locus were prepared to draw the metatranscript annotation alongside the genomic tracks using the program ezTracks(82).

\section{Copy number analysis of pan-hallmark CRISPR candidates}

The copy number status of A549 and in H460 cells was retrieved from the CCLE (https://portals.broadinstitute.org/ccle/data). Then, we intersected the hg19 coordinates of the pgRNA with the hg19 coordinates of the CCLE copy number data. 
TCGA-LUAD copy number data were downloaded as 'log2 ratio segment means'

1056 using the R package TCGAbiolinks and converted to hg19 coordinates using liftOver.

1057 The values of each candidate were averaged across all TCGA-LUAD samples.

1058

The pan-cancer recurrently amplified or deleted genomic regions were 1059 downloaded from the

ICGC

Data

Portal

1060 (https://dcc.icgc.org/releases/PCAWG/consensus_cnv/GISTIC_analysis/all_lesions.c 1061 onf_95.rmcnv.pt_170207.txt.gz). Then, we searched for overlaps between each 1062 candidate and the recurrent copy number altered regions ("Wide Peak Limits"). The 1063 differences in the proportions of amplified, deleted, or non-copy number altered hits versus non-hits were tested using Fisher's exact tests. 
1065

1066

1067

1068

1069

1070

1071

1072

1073

1074

1075

1076

1077

1078

1079

1080

1081

1082

1083

1084

1085

1086

1087

1088

1089

1090

1091

1092

1093

1094

1095

1096

\section{References}

1. Bray F, Ferlay J, Soerjomataram I, Siegel RL, Torre LA, Jemal A. Global cancer statistics 2018: GLOBOCAN estimates of incidence and mortality worldwide for 36 cancers in 185 countries. CA Cancer J Clin [Internet]. Wiley; 2018 [cited 2020 Sep 14];68:394-424. Available from: https://acsjournals.onlinelibrary.wiley.com/doi/full/10.3322/caac.21492

2. Gridelli C, Rossi A, Carbone DP, Guarize J, Karachaliou N, Mok T, et al. Nonsmall-cell lung cancer [Internet]. Nat. Rev. Dis. Prim. Nature Publishing Group; 2015 [cited 2021 Jun 7]. Available from:

https://pubmed.ncbi.nlm.nih.gov/27188576/

3. Salgia R, Pharaon R, Mambetsariev I, Nam A, Sattler M. The improbable targeted therapy: KRAS as an emerging target in non-small cell lung cancer (NSCLC). Cell Reports Med. Cell Press; 2021;2:100186.

4. Rotow J, Bivona TG. Understanding and targeting resistance mechanisms in NSCLC [Internet]. Nat. Rev. Cancer. Nature Publishing Group; 2017 [cited 2021 Apr 27]. page 637-58. Available from:

https://pubmed.ncbi.nlm.nih.gov/29068003/

5. Hong DS, Fakih MG, Strickler JH, Desai J, Durm GA, Shapiro GI, et al. KRASG12C Inhibition with Sotorasib in Advanced Solid Tumors. https://doi.org/101056/NEJMoa1917239 [Internet]. Massachusetts Medical Society; 2020 [cited 2021 Sep 8];383:1207-17. Available from: https://www.nejm.org/doi/full/10.1056/NEJMoa1917239

6. Canon J, Rex K, Saiki AY, Mohr C, Cooke K, Bagal D, et al. The clinical KRAS(G12C) inhibitor AMG 510 drives anti-tumour immunity. Nat 2019 5757781 [Internet]. Nature Publishing Group; 2019 [cited 2021 Sep 8];575:217-23. Available from: https://www.nature.com/articles/s41586-0191694-1

7. Uszczynska-Ratajczak B, Lagarde J, Frankish A, Guigó R, Johnson R. Towards a complete map of the human long non-coding RNA transcriptome. Nat Rev Genet [Internet]. 2018 [cited 2018 Jun 25];19:535-48. Available from: http://www.ncbi.nlm.nih.gov/pubmed/29795125

8. Ma L, Cao J, Liu L, Du Q, Li Z, Zou D, et al. LncBook: a curated 
knowledgebase of human long non-coding RNAs. Nucleic Acids Res [Internet]. Oxford University Press; 2019 [cited 2018 Oct 25];47:D128-34. Available from: https://academic.oup.com/nar/article/47/D1/D128/5133669

9. Volders PJ, Anckaert J, Verheggen K, Nuytens J, Martens L, Mestdagh P, et al. Lncipedia 5: Towards a reference set of human long non-coding rnas. Nucleic Acids Res [Internet]. Oxford University Press; 2019 [cited 2021 Jun 7];47:D135-9. Available from: https://Incipedia.org

10. Hon C-C, Ramilowski JA, Harshbarger J, Bertin N, Rackham OJL, Gough J, et al. An atlas of human long non-coding RNAs with accurate $5^{\prime}$ ends. Nature [Internet]. Nature Research; 2017 [cited 2017 Oct 30];543:199-204. Available from: http://www.nature.com/doifinder/10.1038/nature21374

11. Vancura A, Lanzós A, Bosch-Guiteras N, Esteban MT, Gutierrez AH, Haefliger $S$, et al. Cancer LncRNA Census 2 (CLC2): an enhanced resource reveals clinical features of cancer IncRNAs. NAR Cancer [Internet]. Oxford Academic; 2021 [cited 2021 Apr 28];3. Available from: https://academic.oup.com/narcancer/article/doi/10.1093/narcan/zcab013/6225 859

12. Statello L, Guo CJ, Chen LL, Huarte M. Gene regulation by long non-coding RNAs and its biological functions [Internet]. Nat. Rev. Mol. Cell Biol. Nature Research; 2021 [cited 2021 Jun 7]. page 96-118. Available from: https://pubmed.ncbi.nlm.nih.gov/33353982/

13. Montes M, Lubas M, Arendrup FS, Mentz B, Rohatgi N, Tumas S, et al. The long non-coding RNA MIR31HG regulates the senescence associated secretory phenotype. Nat Commun [Internet]. Nature Research; 2021 [cited 2021 Jun 8];12. Available from: https://pubmed.ncbi.nlm.nih.gov/33911076/

14. Lee B, Sahoo A, Marchica J, Holzhauser E, Chen X, Li JL, et al. The long noncoding RNA SPRIGHTLY acts as an intranuclear organizing hub for premRNA molecules. Sci Adv [Internet]. American Association for the Advancement of Science; 2017 [cited 2021 Jun 8];3. Available from: https://pubmed.ncbi.nlm.nih.gov/28508063/

15. John Liu S, Malatesta M, Lien B V., Saha P, Thombare SS, Hong SJ, et al. CRISPRi-based radiation modifier screen identifies long non-coding RNA 
therapeutic targets in glioma. Genome Biol [Internet]. BioMed Central Ltd.; 2020 [cited 2021 Jun 7];21. Available from: https://pubmed.ncbi.nlm.nih.gov/32234056/

16. Leucci E, Vendramin R, Spinazzi M, Laurette $\mathrm{P}$, Fiers M, Wouters J, et al. Melanoma addiction to the long non-coding RNA SAMMSON. Nature. England; 2016;531:518-22.

17. Esposito R, Bosch N, Lanzós A, Polidori T, Pulido-Quetglas C, Johnson R. Hacking the cancer genome: Profiling therapeutically-actionable long noncoding RNAs using CRISPR-Cas9 screening. Cancer Cell. 2019;15:54557.

18. Liu SJ, Horlbeck MA, Cho SW, Birk HS, Malatesta M, He D, et al. CRISPRibased genome-scale identification of functional long non-coding RNA loci in human cells HHS Public Access IncRNA knockdown can perturb complex transcriptional networks in a cell type-specific manner. These data underscore the functional importance. Science (80- ). 2017;06:1-19.

19. Joung J, Konermann S, Gootenberg JS, Abudayyeh OO, Platt RJ, Brigham MD, et al. Genome-scale CRISPR-Cas9 knockout and transcriptional activation screening. Nat Protoc. England; 2017;12:828-63.

20. Bester AC, Lee JD, Chavez A, Lee Y-RR, Nachmani D, Vora S, et al. An Integrated Genome-wide CRISPRa Approach to Functionalize IncRNAs in Drug Resistance. Cell [Internet]. United States: Elsevier Inc.; 2018;173:649664.e20. Available from: https://doi.org/10.1016/j.cell.2018.03.052

21. Hay M, Thomas DW, Craighead JL, Economides C, Rosenthal J. Clinical development success rates for investigational drugs. Nat Biotechnol 2014321 [Internet]. Nature Publishing Group; 2014 [cited 2021 Sep 14];32:40-51. Available from: https://www.nature.com/articles/nbt.2786

22. MacLeod AR, Crooke ST. RNA Therapeutics in Oncology: Advances, Challenges, and Future Directions. J Clin Pharmacol [Internet]. Blackwell Publishing Inc.; 2017 [cited 2021 Jun 8];57:S43-59. Available from: https://accp1.onlinelibrary.wiley.com/doi/full/10.1002/jcph.957

23. Aparicio-Prat E, Arnan C, Sala I, Bosch N, Guigó R, Johnson R. DECKO: Single-oligo, dual-CRISPR deletion of genomic elements including long non- 
coding RNAs. BMC Genomics [Internet]. BioMed Central; 2015 [cited 2018 Mar 28];16:846. Available from: http://bmcgenomics.biomedcentral.com/articles/10.1186/s12864-015-2086-z

24. Furlan G, Gutierrez Hernandez N, Huret C, Galupa R, van Bemmel JG, Romito A, et al. The Ftx Noncoding Locus Controls $X$ Chromosome Inactivation Independently of Its RNA Products. Mol Cell. Cell Press; 2018;70:462-472.e8.

25. George MR, Duan Q, Nagle A, Kathiriya IS, Huang Y, Rao K, et al. Minimal in vivo requirements for developmentally regulated cardiac long intergenic noncoding RNAs. Dev [Internet]. Company of Biologists Ltd; 2019 [cited 2021 May 3];146. Available from: https://pubmed.ncbi.nlm.nih.gov/31784461/

26. Perry RBT, Hezroni H, Goldrich MJ, Ulitsky I. Regulation of Neuroregeneration by Long Noncoding RNAs. Mol Cell. Cell Press; 2018;72:553-567.e5.

27. Lee HJ, Gopalappa R, Sunwoo H, Choi SW, Ramakrishna S, Lee JT, et al. En bloc and segmental deletions of human XIST reveal X chromosome inactivation-involving RNA elements. Nucleic Acids Res [Internet]. Oxford University Press; 2019 [cited 2021 Apr 28];47:3875-87. Available from: https://academic.oup.com/nar/article/47/8/3875/5345153

28. You B-H, Yoon S-H, Nam J-W. High-confidence coding and noncoding transcriptome maps. Genome Res [Internet]. 2017 [cited 2018 Jan 3];27:105062. Available from: http://www.ncbi.nlm.nih.gov/pubmed/28396519

29. Frankish A, Diekhans M, Ferreira AM, Johnson R, Jungreis I, Loveland J, et al. GENCODE reference annotation for the human and mouse genomes. Nucleic Acids Res [Internet]. Oxford University Press; 2019 [cited 2021 Jun 7];47:D766-73. Available from: https://pubmed.ncbi.nlm.nih.gov/30357393/

30. Davis CA, Hitz BC, Sloan CA, Chan ET, Davidson JM, Gabdank I, et al. The Encyclopedia of DNA elements (ENCODE): Data portal update. Nucleic Acids Res [Internet]. Oxford University Press; 2018 [cited 2021 Apr 28];46:D794801. Available from: https://pubmed.ncbi.nlm.nih.gov/29126249/

31. Dunham I, Kundaje A, Aldred SF, Collins PJ, Davis CA, Doyle F, et al. An integrated encyclopedia of DNA elements in the human genome. Nature [Internet]. Nature Publishing Group; 2012 [cited 2016 Dec 20];489:57-74. Available from: http://www.ncbi.nlm.nih.gov/pubmed/22955616 
1193

1194

1195

1196

1197

1198

1199

1200

1201

1202

1203

1204

1205

1206

1207

1208

1209

1210

1211

1212

1213

1214

1215

1216

1217

1218

1219

1220

1221

1222

1223

1224

32. Imkeller K, Ambrosi G, Boutros M, Huber W. Modelling asymmetric count ratios in CRISPR screens to decrease experiment size and improve phenotype detection. bioRxiv [Internet]. Cold Spring Harbor Laboratory; 2019 [cited 2020 Sep 23];699348. Available from: https://doi.org/10.1101/699348

33. Brower M, Carney DN, Oie HK, Gazdar AF, Minna JD. Growth of Cell Lines and Clinical Specimens of Human Non-Small Cell Lung Cancer in a Serumfree Defined Medium. Cancer Res. 1986;46.

34. DJ G, SA A, GJ T, P A, JH K, H D, et al. In vitro cultivation of human tumors: Establishment of cell lines derived from a series of solid tumors. J Natl Cancer Inst [Internet]. J Natl Cancer Inst; 1973 [cited 2020 Sep 10];51:1417-23. Available from: https://pubmed.ncbi.nlm.nih.gov/4357758/

35. Stojic L, Lun ATL, Mangei J, Mascalchi P, Quarantotti V, Barr AR, et al. Specificity of RNAi, LNA and CRISPRi as loss-of-function methods in transcriptional analysis. Nucleic Acids Res [Internet]. 2018 [cited 2018 Jul 29];46:5950-66. Available from:

http://www.ncbi.nlm.nih.gov/pubmed/29860520

36. Ota T, Suzuki Y, Nishikawa T, Otsuki T, Sugiyama T, Irie R, et al. Complete sequencing and characterization of 21,243 full-length human cDNAs. Nat Genet [Internet]. Nat Genet; 2004 [cited 2021 Jun 7];36:40-5. Available from: https://pubmed.ncbi.nlm.nih.gov/14702039/

37. Hanahan D, Weinberg RA. Hallmarks of cancer: The next generation [Internet]. Cell. Cell; 2011 [cited 2020 Sep 20]. page 646-74. Available from: https://pubmed.ncbi.nlm.nih.gov/21376230/

38. Bester AC, Lee JD, Chavez A, Church GM, Clohessy JG, Paolo P, et al. An Integrated Genome-wide CRISPRa Approach to Functionalize IncRNAs in Drug Resistance In Brief A CRISPR activation screen identifies both coding and noncoding pathways involved in resistance to chemotherapy. Identification of Drug Resistance Coding and IncRNA Networks Dual Coding \& IncRNA CRISPRa Screening In Vitro and In Vivo Validation Bester et al Article An Integrated Genome-wide CRISPRa Approach to Functionalize IncRNAs in Drug Resistance. Cell [Internet]. 2018 [cited 2021 Apr 28];173:649-652.e20. Available from: https://doi.org/10.1016/j.cell.2018.03.052 
1225

1226

1227

1228

1229

1230

1231

1232

1233

1234

1235

1236

1237

1238

1239

1240

1241

1242

1243

1244

1245

1246

1247

1248

1249

1250

1251

1252

1253

1254

1255

1256

39. Konermann S, Brigham MD, Trevino AE, Joung J, Abudayyeh OO, Barcena C, et al. Genome-scale transcriptional activation by an engineered CRISPR-Cas 9 complex. Nature [Internet]. 2015 [cited 2017 May 11];517:583-8. Available from: http://www.nature.com/articles/nature14136

40. Zhu S, Li W, Liu J, Chen C-H, Liao Q, Xu P, et al. Genome-scale deletion screening of human long non-coding RNAs using a paired-guide RNA CRISPR-Cas9 library. Nat Biotechnol [Internet]. Nature Research; 2016 [cited 2016 Dec 21];34:1279-86. Available from: http://www.nature.com/doifinder/10.1038/nbt.3715

41. Beermann J, Kirste D, Iwanov K, Lu D, Kleemiß F, Kumarswamy R, et al. A large shRNA library approach identifies IncRNA Ntep as an essential regulator of cell proliferation. Cell Death Differ [Internet]. England; 2017 [cited 2018 Mar 28];25:307-18. Available from:

https://www.nature.com/articles/cdd2017158.pdf?origin=ppub

42. Zhang M, Lin B, Liu Y, Huang T, Chen M, Lian D, et al. LINC00324 affects non-small cell lung cancer cell proliferation and invasion through regulation of the miR-139-5p/IGF1R axis. Mol Cell Biochem [Internet]. Springer; 2020 [cited 2021 Jun 7];473:193-202. Available from:

https://pubmed.ncbi.nlm.nih.gov/32734536/

43. Zeng Z, Zhao G, Rao C, Hua G, Yang M, Miao X, et al. Knockdown of IncRNA ZFAS1-suppressed non-small cell lung cancer progression via targeting the miR-150-5p/HMGA2 signaling. J Cell Biochem [Internet]. Wiley-Liss Inc.; 2020 [cited 2021 Jun 7];121:3814-24. Available from:

https://pubmed.ncbi.nlm.nih.gov/31692094/

44. Zheng S, Zhang X, Wang X, Li J. MIR31HG promotes cell proliferation and invasion by activating the $\mathrm{Wnt} / \beta$-catenin signaling pathway in non-small cell lung cancer. Oncol Lett [Internet]. Spandidos Publications; 2019 [cited 2021 Jun 7];17:221-9. Available from: /pmc/articles/PMC6313218/

45. Lv J, Qiu M, Xia W, Liu C, Xu Y, Wang J, et al. High expression of long noncoding RNA SBF2-AS1 promotes proliferation in non-small cell lung cancer. J Exp Clin Cancer Res [Internet]. BioMed Central Ltd.; 2016 [cited 2021 Jun 7];35:1-13. Available from: 
https://jeccr.biomedcentral.com/articles/10.1186/s13046-016-0352-9

46. Wang $\mathrm{H}$, Feng L, Zheng $\mathrm{Y}$, Li W, Liu L, Xie S, et al. Linc00680 promotes the progression of non-small cell lung cancer and functions as a sponge of mir410-3p to enhance hmgb1 expression. Onco Targets Ther [Internet]. Dove Medical Press Ltd; 2020 [cited 2021 Jun 7];13:8183-96. Available from: https://pubmed.ncbi.nlm.nih.gov/32904350/

47. Sun CC, Li SJ, Li G, Hua RX, Zhou XH, Li DJ. Long Intergenic Noncoding RNA 00511 Acts as an Oncogene in Non-small-cell Lung Cancer by Binding to EZH2 and Suppressing p57. Mol Ther - Nucleic Acids. Elsevier Inc; 2016;5:e385.

48. Peng W, Feng J. Long noncoding RNA LUNAR1 associates with cell proliferation and predicts a poor prognosis in diffuse large B-cell lymphoma. Biomed Pharmacother [Internet]. Elsevier Masson SAS; 2016 [cited 2021 Jun 7];77:65-71. Available from: https://pubmed.ncbi.nlm.nih.gov/26796267/

49. Cui C, Zhai D, Cai L, Duan Q, Xie L, Yu J. Long noncoding rna heih promotes colorectal cancer tumorigenesis via counteracting mir-939-mediated transcriptional repression of Bcl-XI. Cancer Res Treat [Internet]. Korean Cancer Association; 2018 [cited 2021 Jun 7];50:992-1008. Available from: https://pubmed.ncbi.nlm.nih.gov/29081216/

50. Liu Y, Cao Z, Wang Y, Guo Y, Xu P, Yuan P, et al. Genome-wide screening for functional long noncoding RNAs in human cells by Cas9 targeting of splice sites. Nat Biotechnol. 2018;36.

51. Hanna N, Johnson D, Temin S, Baker S, Brahmer J, Ellis PM, et al. Systemic therapy for stage IV non-small-cell lung cancer: American Society of clinical oncology clinical practice guideline update. J Clin Oncol [Internet]. American Society of Clinical Oncology; 2017 [cited 2020 Sep 10];35:3484-515. Available from: https://pubmed.ncbi.nlm.nih.gov/28806116/

52. Lu QC, Rui HH, Guo ZL, Xie W, Shan S, Ren T. LncRNA-DANCR contributes to lung adenocarcinoma progression by sponging miR-496 to modulate mTOR expression. J Cell Mol Med [Internet]. Blackwell Publishing Inc.; 2018 [cited 2021 Jun 7];22:1527-37. Available from: https://pubmed.ncbi.nlm.nih.gov/29266795/ 
1289

1290

1291

1292

1293

1294

1295

1296

1297

1298

1299

1300

1301

1302

1303

1304

1305

1306

1307

1308

1309

1310

1311

1312

1313

1314

1315

1316

1317

1318

1319

1320

53. Li S, Wu D, Jia H, Zhang Z. Long non-coding RNA LRRC75A-AS1 facilitates triple negative breast cancer cell proliferation and invasion via functioning as a ceRNA to modulate BAALC. Cell Death Dis [Internet]. Springer Nature; 2020 [cited 2021 Jun 7];11. Available from: https://pubmed.ncbi.nlm.nih.gov/32811810/

54. Han L, Li Z, Jiang Y, Jiang Z, Tang L. SNHG29 regulates miR-223$3 p / C T N N D 1$ axis to promote glioblastoma progression via Wnt/B-catenin signaling pathway. Cancer Cell Int [Internet]. BioMed Central Ltd.; 2019 [cited 2021 Jun 7];19. Available from: https://pubmed.ncbi.nlm.nih.gov/31889897/

55. Zhang Y, Li Y. Long non-coding RNA NORAD contributes to the proliferation, invasion and EMT progression of prostate cancer via the miR-30a5p/RAB11A/WNT/B-catenin pathway. Cancer Cell Int [Internet]. BioMed Central Ltd; 2020 [cited 2021 Jun 7];20:571. Available from: http://www.ncbi.nlm.nih.gov/pubmed/33292272

56. Lai F, Damle SS, Ling KK, Rigo F. Directed RNase H Cleavage of Nascent Transcripts Causes Transcription Termination. Mol Cell [Internet]. Cell Press; 2020 [cited 2021 Jun 7];77:1032-1043.e4. Available from:

https://pubmed.ncbi.nlm.nih.gov/31924447/

57. CRISPRi-based genome-scale identification of functional long noncoding RNA loci in human cells. Science (80- ). 355:aah7111.

58. Marín-Béjar O, Mas AM, González J, Martinez D, Athie A, Morales X, et al. The human IncRNA LINC-PINT inhibits tumor cell invasion through a highly conserved sequence element. Genome Biol [Internet]. 2017 [cited 2018 Jan 16];18:202. Available from: http://genomebiology.biomedcentral.com/articles/10.1186/s13059-017-1331-y

59. Huarte M. The emerging role of IncRNAs in cancer. Nat Med [Internet]. 2015 [cited 2016 Jun 29];21:1253-61. Available from: http://www.nature.com/doifinder/10.1038/nm.3981

60. Seo JS, Ju YS, Lee WC, Shin JY, Lee JK, Bleazard T, et al. The transcriptional landscape and mutational profile of lung adenocarcinoma. Genome Res [Internet]. Genome Res; 2012 [cited 2021 Jun 7];22:2109-19. Available from: https://pubmed.ncbi.nlm.nih.gov/22975805/ 
1321

1322

1323

1324

1325

1326

1327

1328

1329

1330

1331

1332

1333

1334

1335

1336

1337

1338

1339

1340

1341

1342

1343

1344

1345

1346

1347

1348

1349

1350

1351

61. Blokhin I, Khorkova O, Hsiao J, Wahlestedt C. Developments in IncRNA drug discovery: where are we heading? Expert Opin Drug Discov [Internet]. 2018 [cited 2018 Oct 25];13:837-49. Available from: http://www.ncbi.nlm.nih.gov/pubmed/30078338

62. Dhuri K, Bechtold C, Quijano E, Pham H, Gupta A, Vikram A, et al. Antisense Oligonucleotides: An Emerging Area in Drug Discovery and Development. J Clin Med [Internet]. Multidisciplinary Digital Publishing Institute (MDPI); 2020 [cited 2020 Nov 15];9:2004. Available from: /pmc/articles/PMC7355792/?report=abstract

63. Kaczmarek JC, Kowalski PS, Anderson DG. Advances in the delivery of RNA therapeutics: From concept to clinical reality [Internet]. Genome Med. BioMed Central Ltd.; 2017 [cited 2020 Sep 14]. page 1-16. Available from: https://genomemedicine.biomedcentral.com/articles/10.1186/s13073-0170450-0

64. Matsui M, Corey DR. Non-coding RNAs as drug targets [Internet]. Nat. Rev. Drug Discov. Nature Publishing Group; 2017 [cited 2020 Sep 25]. page 16779. Available from: https://pubmed.ncbi.nlm.nih.gov/27444227/

65. Wang Y, Guo S, Li D, Tang Y, Li L, Su L, et al. YIPF2 promotes chemotherapeutic agent-mediated apoptosis via enhancing TNFRSF10B recycling to plasma membrane in non-small cell lung cancer cells. Cell Death Dis [Internet]. Springer Nature; 2020 [cited 2020 Sep 20];11. Available from: https://pubmed.ncbi.nlm.nih.gov/32303681/

66. Ruan Z, Xu Z, Li Z, Lv Y. Integral analyses of survival-related long non-coding RNA MIR210HG and its prognostic role in colon cancer. Oncol Lett [Internet]. Spandidos Publications; 2019 [cited 2020 Sep 12];18:1107-16. Available from: http://starbase.sysu.

67. Ma M, Zhang Y, Weng M, Hu Y, Xuan Y, Hu YR, et al. IncRNA GCAWKR Promotes Gastric Cancer Development by Scaffolding the Chromatin Modification Factors WDR5 and KAT2A. Mol Ther [Internet]. Cell Press; 2018 [cited 2021 Jun 7];26:2658-68. Available from: /pmc/articles/PMC6225079/

68. Unger C, Kramer N, Walzl A, Scherzer M, Hengstschläger M, Dolznig H. Modeling human carcinomas: Physiologically relevant 3D models to improve 
anti-cancer drug development [Internet]. Adv. Drug Deliv. Rev. Elsevier; 2014 [cited 2020 Sep 24]. page 50-67. Available from:

https://pubmed.ncbi.nlm.nih.gov/25453261/

69. Han K, Pierce SE, Li A, Spees K, Anderson GR, Seoane JA, et al. CRISPR screens in cancer spheroids identify 3D growth-specific vulnerabilities. Nature [Internet]. Nature Research; 2020 [cited 2020 Aug 4];580:136-41. Available from: https://pubmed.ncbi.nlm.nih.gov/32238925/

70. Sachs N, de Ligt J, Kopper O, Gogola E, Bounova G, Weeber F, et al. A Living Biobank of Breast Cancer Organoids Captures Disease Heterogeneity. Cell [Internet]. Cell Press; 2018 [cited 2021 Jun 7];172:373-386.e10. Available from: https://doi.org/10.1016/j.cell.2017.11.010

71. Carlevaro-Fita J, Polidori T, Das M, Navarro C, Zoller TI, Johnson R. Ancient exapted transposable elements promote nuclear enrichment of human long noncoding RNAs. Genome Res [Internet]. 2019 [cited 2019 Feb 6];29:208-22. Available from: http://www.ncbi.nlm.nih.gov/pubmed/30587508

72. Ramilowski JA, Yip CW, Agrawal S, Chang JC, Ciani Y, Kulakovskiy I V., et al. Functional annotation of human long noncoding RNAs via molecular phenotyping. Genome Res [Internet]. NLM (Medline); 2020 [cited 2020 Sep 22];30:1060-72. Available from:

http://www.genome.org/cgi/doi/10.http://creativecommons.org/licenses/by/4.0/.; www.genome.orgwww.genome.org

73. Kellis M, Wold B, Snyder MP, Bernstein BE, Kundaje A, Marinov GK, et al. Defining functional DNA elements in the human genome [Internet]. Proc. Natl. Acad. Sci. U. S. A. National Academy of Sciences; 2014 [cited 2021 Apr 30]. page 6131-8. Available from: www.ncbi.nlm.nih.gov/geo

74. Kanehisa M, Furumichi M, Tanabe M, Sato Y, Morishima K. KEGG: New perspectives on genomes, pathways, diseases and drugs. Nucleic Acids Res [Internet]. Oxford University Press; 2017 [cited 2021 Jun 7];45:D353-61. Available from: https://pubmed.ncbi.nlm.nih.gov/27899662/

75. Subramanian A, Tamayo P, Mootha VK, Mukherjee S, Ebert BL, Gillette MA, et al. Gene set enrichment analysis: A knowledge-based approach for interpreting genome-wide expression profiles. Proc Natl Acad Sci U S A 
[Internet]. National Academy of Sciences; 2005 [cited 2021 Apr 30];102:15545-50. Available from: www.pnas.orgcgidoi10.1073pnas.0506580102

76. Apostolopoulou K, Pateras IS, Evangelou K, Tsantoulis PK, Liontos M, Kittas $C$, et al. Gene amplification is a relatively frequent event leading to ZBTB7A (Pokemon) overexpression in non-small cell lung cancer. J Pathol [Internet]. J Pathol; 2007 [cited 2021 Jun 7];213:294-302. Available from:

https://pubmed.ncbi.nlm.nih.gov/17907153/

77. Zhijun Z, Jingkang $\mathrm{H}$. MicroRNA-520e suppresses non-small-cell lung cancer cell growth by targeting Zbtb7a-mediated Wnt signaling pathway. Biochem Biophys Res Commun [Internet]. Elsevier B.V.; 2017 [cited 2021 Jun 7];486:49-56. Available from: https://pubmed.ncbi.nlm.nih.gov/28242196/

78. Berkers CR, Maddocks ODK, Cheung EC, Mor I, Vousden KH. Metabolic regulation by p53 family members [Internet]. Cell Metab. Cell Metab; 2013 [cited 2021 Apr 30]. page 617-33. Available from: https://pubmed.ncbi.nlm.nih.gov/23954639/

79. Maeda T, Hobbs RH, Morghoub T, Guernah I, Zelent A, Cordon-Cardo C, et al. Role of the proto-oncogene Pokemon in cellular transformation and ARF repression. Nature [Internet]. Nature; 2005 [cited 2021 Apr 30];433:278-85. Available from: https://pubmed.ncbi.nIm.nih.gov/15662416/

80. Zhang YQ, Xiao CX, Lin BY, Shi Y, Liu YP, Liu JJ, et al. Silencing of Pokemon Enhances Caspase-Dependent Apoptosis via Fas- and Mitochondria-Mediated Pathways in Hepatocellular Carcinoma Cells. PLoS One [Internet]. PLoS One; 2013 [cited 2021 Jun 7];8. Available from: https://pubmed.ncbi.nlm.nih.gov/23874836/

81. Constantinou C, Spella M, Chondrou V, Patrinos GP, Papachatzopoulou A, Sgourou A. The multi-faceted functioning portrait of LRF/ZBTB7A [Internet]. Hum. Genomics. BioMed Central Ltd.; 2019 [cited 2021 Jun 7]. page 1-14. Available from: https://doi.org/10.1186/s40246-019-0252-0

82. Guillen-Ramirez HA, Johnson R. ezTracks v0.1.0. 2021 [cited 2021 Jun 7]; Available from: https://zenodo.org/record/4749431

83. Doench JG. Am I ready for CRISPR? A user's guide to genetic screens. Nat 
Rev Genet [Internet]. Nature Publishing Group; 2017 [cited 2018 Feb 20];19:67-80. Available from: http://www.ncbi.nlm.nih.gov/pubmed/29199283

84. Agrotis A, Ketteler R. A new age in functional genomics using CRISPR/Cas9 in arrayed library screening. Front Genet [Internet]. 2015 [cited 2018 Mar 28];6:300. Available from: http://www.ncbi.nlm.nih.gov/pubmed/26442115

85. Leucci E, Vendramin R, Spinazzi M, Laurette P, Fiers M, Wouters J, et al. Melanoma addiction to the long non-coding RNA SAMMSON. Nature. England; 2016;531:518-22.

86. Hosono Y, Niknafs YS, Prensner JR, Feng FY, Zhou W, Chinnaiyan AM. Oncogenic Role of THOR , a Conserved Cancer / Testis Non-coding RNA. Cell [Internet]. Elsevier Inc.; 2017;171:1559-1561.e20. Available from: https://doi.org/10.1016/j.cell.2017.11.040

87. Joung J, Engreitz JM, Konermann S, Abudayyeh OO, Verdine VK, Aguet F, et al. Genome-scale activation screen identifies a IncRNA locus regulating a gene neighbourhood. Nature [Internet]. England: Nature Publishing Group; 2017 [cited 2018 Mar 28];548:343-6. Available from: http://www.nature.com/doifinder/10.1038/nature23451

88. Ramilowski JA, Yip CW, Agrawal S, Chang J-C, Ciani Y, Kulakovskiy I V., et al. Functional Annotation of Human Long Non-Coding RNAs via Molecular Phenotyping. bioRxiv [Internet]. Cold Spring Harbor Laboratory; 2019 [cited 2020 Jun 5];700864. Available from: http://dx.doi.org/10.1101/700864\%0A

89. Gagnon KT, Corey DR. Guidelines for Experiments Using Antisense Oligonucleotides and Double-Stranded RNAs. Nucleic Acid Ther [Internet]. Mary Ann Liebert Inc.; 2019 [cited 2021 May 3];29:116-22. Available from: /pmc/articles/PMC6555184/

90. Mokhtari RB, Homayouni TS, Baluch N, Morgatskaya E, Kumar S, Das B, et al. Combination therapy in combating cancer [Internet]. Oncotarget. Impact Journals LLC; 2017 [cited 2021 Jun 7]. page 38022-43. Available from: /pmc/articles/PMC5514969/

91. Ritter N, Ali T, Kopitchinski N, Schuster P, Beisaw A, Hendrix DA, et al. The IncRNA Locus Handsdown Regulates Cardiac Gene Programs and Is Essential for Early Mouse Development. Dev Cell [Internet]. Cell Press; 2019 
[cited 2021 Jun 7];50:644-657.e8. Available from:

https://pubmed.ncbi.nlm.nih.gov/31422919/

92. Lavalou P, Eckert H, Damy L, Constanty F, Majello S, Bitetti A, et al.

Strategies for Genetic Inactivation of Long Noncoding RNAs in Zebrafish. RNA [Internet]. 2019 [cited 2019 May 15];rna.069484.118. Available from:

http://www.ncbi.nlm.nih.gov/pubmed/31043511

93. Lagarde J, Uszczynska-Ratajczak B, Carbonell S, Pérez-Lluch S, Abad A, Davis C, et al. High-throughput annotation of full-length long noncoding RNAs with capture long-read sequencing. Nat Genet [Internet]. 2017 [cited 2018 Jan 3];49:1731-40. Available from: http://www.ncbi.nlm.nih.gov/pubmed/29106417

94. Han K, Pierce SE, Li A, Spees K, Anderson GR, Seoane JA, et al. CRISPR screens in cancer spheroids identify 3D growth-specific vulnerabilities. Nature [Internet]. Nature Research; 2020 [cited 2020 Sep 15];580:136-41. Available from: https://doi.org/10.1038/s41586-020-2099-x

95. Pulido-Quetglas C, Aparicio-Prat E, Arnan C, Polidori T, Hermoso T, Palumbo E, et al. Scalable Design of Paired CRISPR Guide RNAs for Genomic Deletion. PLOS Comput Biol [Internet]. Public Library of Science (PLoS); 2017;13:e1005341. Available from: http://dx.doi.org/10.1371/journal.pcbi.1005341

96. Pertea M, Pertea GM, Antonescu CM, Chang T-C, Mendell JT, Salzberg SL. StringTie enables improved reconstruction of a transcriptome from RNA-seq reads. Nat Biotechnol [Internet]. 2015 [cited 2018 Jan 3];33:290-5. Available from: http://www.ncbi.nlm.nih.gov/pubmed/25690850

97. Li B, Dewey CN. RSEM: accurate transcript quantification from RNA-Seq data with or without a reference genome. BMC Bioinformatics [Internet]. BioMed Central; 2011 [cited 2016 Dec 23];12:323. Available from: http://www.ncbi.nlm.nih.gov/pubmed/21816040

98. Ernst J, Kellis M. Discovery and characterization of chromatin states for systematic annotation of the human genome. Nat Biotechnol [Internet]. Nat Biotechnol; 2010 [cited 2021 Jun 7];28:817-25. Available from: https://pubmed.ncbi.nlm.nih.gov/20657582/ 
screening of human long non-coding RNAs using a paired-guide RNA CRISPR-Cas9 library. Nat Biotechnol [Internet]. Nature Research; 2016 [cited 2016 Nov 4];34:1279-86. Available from: http://www.nature.com/doifinder/10.1038/nbt.3715

100. DECKO: single-oligo, dual-CRISPR deletion of genomic elements including long non-coding RNAs. BMC Genomics. 16:846.

101. Sanjana NE, Shalem O, Zhang F. Improved vectors and genome-wide libraries for CRISPR screening. Nat Methods [Internet]. United States: NIH Public Access; 2014 [cited 2018 Mar 28];11:783-4. Available from: http://www.nature.com/articles/nmeth.3047

102. Bergadà-Pijuan J, Pulido-Quetglas C, Vancura A, Johnson R. CASPR, an analysis pipeline for single and paired guide RNA CRISPR screens, reveals optimal target selection for long non-coding RNAs. Bioinformatics. 2020;36:1673-80.

103. Perez AR, Pritykin Y, Vidigal JA, Chhangawala S, Zamparo L, Leslie CS, et al. GuideScan software for improved single and paired CRISPR guide RNA design. Nat Biotechnol [Internet]. Nature Publishing Group; 2017 [cited 2021 Jun 7];35:347-9. Available from: https://pubmed.ncbi.nlm.nih.gov/28263296/

104. Wang B, Wang M, Zhang W, Xiao T, Chen CH, Wu A, et al. Integrative analysis of pooled CRISPR genetic screens using MAGeCKFlute. Nat Protoc [Internet]. Nature Publishing Group; 2019 [cited 2021 Jun 7];14:756-80. Available from: https://pubmed.ncbi.nlm.nih.gov/30710114/

105. Kolde R, Laur S, Adler P, Vilo J. Robust rank aggregation for gene list integration and meta-analysis. Bioinformatics [Internet]. Oxford Academic; 2012 [cited 2021 Jun 7];28:573-80. Available from: http://cran.r-project.org/.

106. Poole W, Gibbs DL, Shmulevich I, Bernard B, Knijnenburg TA. Combining dependent P-values with an empirical adaptation of Brown's method. Bioinformatics [Internet]. Oxford University Press; 2016 [cited 2021 Jun 7]. page i430-6. Available from: https://pubmed.ncbi.nlm.nih.gov/27587659/

107. Wilson DJ. The harmonic mean p-value for combining dependent tests. Proc Natl Acad Sci U S A [Internet]. National Academy of Sciences; 2019 [cited 2021 Jun 7];116:1195-200. Available from: 
www.pnas.org/cgi/doi/10.1073/pnas.1814092116

108. Anders S, Pyl PT, Huber W. HTSeq-A Python framework to work with highthroughput sequencing data. Bioinformatics [Internet]. Oxford University Press; 2015 [cited 2021 Jun 7];31:166-9. Available from:

https://pubmed.ncbi.nlm.nih.gov/25260700/

109. Li J, Han L, Roebuck P, Diao L, Liu L, Yuan Y, et al. TANRIC: An Interactive Open Platform to Explore the Function of IncRNAs in Cancer. Cancer Res [Internet]. American Association for Cancer Research; 2015 [cited 2016 Jun 28];75:3728-37. Available from: http://www.ncbi.nlm.nih.gov/pubmed/26208906

110. Shultz LD, Lyons BL, Burzenski LM, Gott B, Chen X, Chaleff S, et al. Human Lymphoid and Myeloid Cell Development in NOD/LtSz- scid IL2R y null Mice Engrafted with Mobilized Human Hemopoietic Stem Cells . J Immunol [Internet]. The American Association of Immunologists; 2005 [cited 2021 Jun 7];174:6477-89. Available from: http://www.jimmunol.org/content/174/10/6477http://www.jimmunol.org/content/ 174/10/6477.full\#ref-list-1

111. Esposito R, Esposito D, Pallante P, Fusco A, Ciccodicola A, Costa V. Oncogenic properties of the antisense IncRNA COMET in BRAF- and RETdriven papillary thyroid carcinomas. Cancer Res [Internet]. American Association for Cancer Research Inc.; 2019 [cited 2021 Jun 8];79:2124-35. Available from: http://cancerres.aacrjournals.org/

112. Bray NL, Pimentel H, Melsted P, Pachter L. Near-optimal probabilistic RNAseq quantification. Nat Biotechnol [Internet]. Nature Publishing Group; 2016 [cited 2021 Jun 7];34:525-7. Available from: https://pubmed.ncbi.nlm.nih.gov/27043002/

113. Pimentel H, Bray NL, Puente S, Melsted P, Pachter L. Differential analysis of RNA-seq incorporating quantification uncertainty. Nat Methods [Internet]. Nature Publishing Group; 2017 [cited 2021 Jun 7];14:687-90. Available from: https://pubmed.ncbi.nlm.nih.gov/28581496/

114. Jawaid W. Provides an R Interface to "Enrichr" [R package enrichR version 3.0]. Comprehensive R Archive Network (CRAN); 2021 [cited 2021 Jun 7]; 
Available from: https://cran.r-project.org/package=enrichR

115. McQuin C, Goodman A, Chernyshev V, Kamentsky L, Cimini BA, Karhohs KW, et al. CellProfiler 3.0: Next-generation image processing for biology. PLOS Biol [Internet]. Public Library of Science; 2018 [cited 2021 Sep 9];16:e2005970. Available from: https://journals.plos.org/plosbiology/article?id=10.1371/journal.pbio. 2005970

116. Seemann SE, Mirza AH, Hansen C, Bang-Berthelsen CH, Garde C, Christensen-Dalsgaard $\mathrm{M}$, et al. The identification and functional annotation of RNA structures conserved in vertebrates. Genome Res [Internet]. 2017 [cited 2017 Sep 2];27:1371-83. Available from: http://www.ncbi.nlm.nih.gov/pubmed/28487280

117. Abascal F, Acosta R, Addleman NJ, Adrian J, Afzal V, Aken B, et al. Expanded encyclopaedias of DNA elements in the human and mouse genomes. Nature [Internet]. Nature Research; 2020 [cited 2021 Jun 7];583:699-710. Available from: https://doi.org/10.1038/s41586-020-2493-4

118. Kent WJ, Sugnet CW, Furey TS, Roskin KM, Pringle TH, Zahler AM, et al. The human genome browser at UCSC. Genome Res [Internet]. Cold Spring Harbor Laboratory Press; 2002 [cited 2017 Apr 20];12:996-1006. Available from: http://www.ncbi.nlm.nih.gov/pubmed/12045153

119. Siepel A, Bejerano G, Pedersen JS, Hinrichs AS, Hou M, Rosenbloom K, et al. Evolutionarily conserved elements in vertebrate, insect, worm, and yeast genomes. Genome Res [Internet]. Cold Spring Harbor Laboratory; 2005 [cited 2017 Aug 25];15:1034-50. Available from: http://dx.doi.org/10.1101/gr.3715005

120. Quinlan AR, Hall IM. BEDTools: a flexible suite of utilities for comparing genomic features. Bioinformatics [Internet]. Oxford University Press (OUP); 2010 [cited 2017 Aug 25];26:841-2. Available from: http://www.ncbi.nlm.nih.gov/pubmed/20110278 


\section{Supplementary information titles and legends}

1575 Supplementary File 1. Composition of CRISPR-del "libDECKO-NSCLC1" library.

1576 This file contains, per each target, the sequence of the pgRNAs and the target gene.

1577 Supplementary File 2. Single screen results of all 10 screens using the CASPR 1578 pipeline.

1579 Supplementary File 3. Results from the target prioritisation pipeline (TPP) (integration 1580 of all 10 screens (pan-hallmark), or split by phenotype (pro=proliferation; cis=cisplatin; 1581 mig=migration).

1582 Supplementary File 4. List of plasmids used in this project. Related to the methods

1583 Supplementary File 5. Tables 1-13. Sequence of oligonucleotides for, PCR qPCR, 1584 ASO, media composition and PCR condition.

1585

1586 Supplementary figures

1587 Supplementary Fig. 1. libDECKO-NSCLC1 library creation.

1588 Supplementary Fig. 2. Assessing screen accuracy.

1589 Supplementary Fig. 3. TPP quality assessment and CNV analysis. R

1590 Supplementary Fig. 4. Tier 2 candidates and cancer hallmarks. R

1591 Supplementary Fig. 5. Further information on CHiLL1 and CHiLL2.

1592 Supplementary Fig. 6. CHiLL1\&2 perturbation impacts disease transcriptome. 